\title{
Statistical evaluation of a new resistance model for cold-formed stainless steel cross-sections subjected to web crippling
}

\author{
M. Bock* , F. X. Mirada and E. Real \\ Department of Construction Engineering, Universitat Politècnica de Catalunya, UPC \\ C/ Jordi Girona, 1-3. 08034 Barcelona, Spain \\ * Corresponding author: Tel: +0034 934054156, Fax: +0034 934054135, e-mail: \\ marina.bock@upc.edu
}

\begin{abstract}
This paper presents a statistical evaluation according to Annex D of EN 1990 (2002) of a new resistance function for web crippling design of cold-formed stainless steel crosssections. This resistance function was derived in Bock et al. (2013) through the use of carefully validated numerical models with the aim to propose a design expression for stainless steel sections, which are currently designed following the provisions for coldformed carbon steel sections given in EN 1993-1-3 (2006). Although it was shown that the proposed design equation is appropriate for application to various stainless steels, the statistical uncertainties in material properties that the different types of stainless steels exhibit require an assessment of various partial safety factors. The statistical assessment showed that the proposed resistance function by Bock et al. (2013) requires adjustment to satisfy the safety level set out in EN 1993-1-4 (2006); A recalibration is performed herein. The web crippling design provisions given in EN 1993-1-3 (2006) and SEI/ASCE 8-02 (2002) American standard for application to stainless steel are also statistically evaluated herein. Comparison with test and numerical data showed that the predictions of the recalibrated resistance function are better suited and consistent than existing design provisions.
\end{abstract}

Keywords: Cold-formed sections, Concentrated loads, Numerical analyses, Stainless steel, Statistical validation, Web crippling

\section{Introduction}

Cold-formed members exhibit a high strength-to-weight ratio which makes them attractive for a variety of structural applications where the use of less material has profound financial and environmental benefits. In particular, cold-formed stainless steel members possess the additional advantages of excellent corrosion resistance and recyclability which may offset the disadvantage of high material cost when cost is considered on a whole life basis. However, high slenderness of cold-formed member makes them more susceptible to local instabilities such as web crippling where the cross-section becomes unstable under concentrated transverse forces. The web crippling design equations given in existing structural design guidance take into account the type of loading and load location. Forces applied through one side of the cross-section flange are defined as one-flange loading, while those acting on both cross-section flanges are defined as two-flange loading. Depending on the location of the load, distinction is made between interior and exterior loading if the load is applied within the span or at the end of the member, respectively. The combination of these situations defines the four loading cases: IOF (interior one-flange), ITF (interior two-flanges), EOF (exterior one-flange) and ETF (exterior two-flanges). This classification is currently adopted in 
SEI/ASCE 8-02 (2002) American standard for application to stainless steel while the design expressions given in EN 1993-1-3 (2006) use relevant categories. Category 1 is the EOF, ETF and ITF counterpart while Category 2 is equivalent to IOF loading.

Web crippling is a complex type of local failure because it includes a large number of factors. Because of this, most existing expressions for web crippling design are empirical in nature and were calibrated by statistical fitting against experimental data. Winter and Pian (1946) proposed the first curve-fitting expression for carbon steel Isections under EOF and IOF loading at Cornell University. After that, many empirical equations have been derived and implemented in the design rules for other cross-section geometries and load cases. Relevant research includes the studies performed by Baehre (1975), Hetrakul and Yu (1978), Wing (1981), Packer (1984), Santaputra et al. (1989), Studnicka (1990), Bhakta et al. (1992), Prabhakaran (1993), Cain et al. (1995), and Gerges (1997). In parallel with these studies on carbon steel, research was also conducted by Tsai (1987), Bakker and Stark (1994), Zhao and Hancock (1992, 1995), Hofmeyer et al. (2001) and Young and Hancock (2001) where analytical models for various types of cross-sections are proposed.

Given the new usage of stainless steel in construction and the urge to provide practising engineers and researchers with design rules, the first version of the current SEI/ASCE 8-02 (2002) American standard for stainless steels, the ANSI/ASCE 8-90 (1991) American standard, adopted the web crippling design provisions for carbon steel. The suitability of this assumption was assessed by Korvink et al. (1995) in the Rand Afrikaans University, where some discrepancies were observed.

The aim of following studies was therefore to achieve better understanding of the effect of material behaviour on web crippling response and to develop appropriate design provisions for stainless steels. While research conducted by Zhou and Young (2006, 2007a, 2007b, 2007c, 2008) focused on the development of web crippling design expressions within the framework of SEI/ASCE 8-02 (2002) American standard and NASPEC-2001 (2001) specifications, Talja and Salmi (1995), Talja (2004), Zilli (2004) and Bock et al. (2013), among other studies, assessed the European code. It is within this latter research, where a new expression adapted from EN 1993-1-3 (2006) was proposed to predict the web crippling resistance of cold-formed stainless steel members. The studied cross-sections were cold-formed square hollow sections (SHS), rectangular hollow sections (RHS) and hat sections. The purpose of this paper is to conduct a statistical evaluation according to Annex D of EN 1990 (2002) to assess the reliability of the proposed design equation by Bock et al. (2013) and provide a safe equation, where recalibration is required, applicable to various stainless steel grades.

\section{Existing design guidance}

\subsection{European design rule EN 1993-1-3}

The web crippling design rules for stainless steel cross-sections given in EN 1993-1-4 (2006) are adopted from the specifications for cold-formed carbon steel members provided by EN 1993-1-3 (2006). The current design approach given in EN 1993-1-3 (2006) to determine the web crippling cross-section design resistance per web $R_{w, R d}$ provides various empirical equations for various load cases (relevant categories) and takes into consideration the number of webs of the cross-section as well as whether they are stiffened or unstiffened. For the case of cross-sections with two or more unstiffened webs, which the proposed equation in Bock et al. (2013) deals with, the resistance is 
given by Eq. (1) where $r$ is the internal radius of the corners, $t$ is the thickness, $\phi$ is the relative angle between the web and the flange, $\mathrm{E}$ is the material Young's modulus and $\sigma_{0.2}$ is the material proof strength. The equation also depends on $\alpha$ and $1_{\mathrm{a}}$, which are a non-dimensional coefficient related to the cross-section geometry and the effective bearing length related to the relevant category, respectively. The values of these parameters for hat sections are given in EN 1993-1-3 (2006) as follows: for Category 1 (EOF) $\alpha=0.057$ and $l_{a}=10 \mathrm{~mm}$; for Category 2 (IOF) $\alpha=0.115$ and $l_{a}=s_{s}$ where $s_{s}$ is the bearing length over which the transversal load is applied. The design formulation includes a partial safety factor $\gamma_{\mathrm{M} 1}$. Despite EN 1993-1-3 (2006) does not explicitly give design rules for the determination of the web crippling resistance for SHS and RHS, Talja and Salmi (1995) proposed to assume coefficients for sheeting with values of $\alpha=0.075$ for Category 1 (EOF) and $\alpha=0.15$ for Category 2 (IOF). This is therefore adopted in the present study; previous investigations have also used this approach (Gardner et al. (2006), Talja and Hradil (2011) and Bock et al. (2013)).

$R_{w, R d}=\alpha t^{2} \sqrt{\sigma_{0.2} E}\left(1-0.1 \sqrt{\frac{r}{t}}\right)\left(0.5+\sqrt{\frac{0.02_{a}}{t}}\right)\left(2.4+\left(\frac{\phi}{90}\right)^{2}\right) / \gamma_{M 1}$

In addition, those cross-sections subjected to the combined action of a bending moment $\mathrm{M}_{\mathrm{Ed}}$ and a transverse force $\mathrm{R}_{\mathrm{Ed}}$ (i.e. interior supports of continuous spans - IOF or Category 2) should satisfy Eqs. (2)-(4) where $M_{c, R d}$ is the moment resistance of the cross-section and $\mathrm{R}_{\mathrm{w}, \mathrm{Rd}}$ is the sum of the local transverse resistances of the individual webs as given by Eq. (1). The web crippling cross-section design resistance for elements under such combination of actions $\mathrm{R}_{\mathrm{WC}-\mathrm{BD}}$ is given by Eq. (5) where $\mathrm{L}$ and $\mathrm{s}_{\mathrm{sL}}$ are defined in Fig. 1.

$$
\begin{aligned}
& \frac{R_{E d}}{R_{w, R d}} \leq 1 \\
& \frac{M_{E d}}{M_{c, R d}} \leq 1 \\
& \frac{R_{E d}}{R_{w, R d}}+\frac{M_{E d}}{M_{c, R d}} \leq 1.25 \\
& R_{W C-B D}=R_{E d}=1.25 /\left(\frac{1}{R_{w, R d}}+\frac{L-s_{S L}}{4 M_{c, R d}}\right) \leq \min \left\{R_{E d}, 4 M_{c, R d} /\left(L-s_{S L}\right)\right\}
\end{aligned}
$$

\subsection{SEI/ASCE 8-02 American standard}

In the American framework, SEI/ASCE 8-02 (2002) provides Eq. (6) and (7) for web crippling design of shapes having single webs and unstiffened flanges, upon which the proposed equation in Bock et al. (2013) is concerned, under IOF loading while for EOF loading, the expression is given in Eq. (8). In these equations, the coefficients $\mathrm{C}_{1}, \mathrm{C}_{2}$, $\mathrm{C}_{3}, \mathrm{C}_{4}$ and $\mathrm{C}_{\theta}$ are defined in Eqs. (9)-(13). Bending and web crippling interaction effects are accounted for as given by Eq. (14) which may be rewritten as Eq. (15), where $\phi_{\mathrm{w}}=0.7$ and $\phi_{\mathrm{b}}=0.85$ are the resistance factor for web crippling and bending, respectively. For consistency reasons, the above mentioned expressions follow EN 1993-1-3 (2006) symbols and SI units.

$$
R_{w, R d}=6.9 \phi_{w} t^{2} C_{1} C_{2} C_{\theta}\left(538-0.74 \frac{h}{t}\right)\left(1+0.007 \frac{s_{S}}{t}\right) \text { if } \frac{s_{S}}{t} \leq 60
$$




$$
\begin{aligned}
& R_{w, R d}=6.9 \phi_{w} t^{2} C_{1} C_{2} C_{\theta}\left(538-0.74 \frac{h}{t}\right)\left(0.75+0.011 \frac{s_{s}}{t}\right) \text { if } \frac{s_{s}}{t}>60 \\
& R_{w, R d}=6.9 \phi_{w} t^{2} C_{3} C_{4} C_{\theta}\left(244-0.57 \frac{h}{t}\right)\left(1+0.01 \frac{s_{s}}{t}\right) \\
& C_{1}=\left(1.22-0.22 \frac{f_{y b}}{227.7}\right) \frac{f_{y b}}{227.7} \text { if } \frac{f_{y b}}{631.35} \leq 1 \text { or } C_{1}=1.69 \text { if } \frac{f_{y b}}{631.35}>1 \\
& C_{2}=\left(1.06-0.06 \frac{r}{t}\right) \leq 1 \\
& C_{3}=\left(1.33-0.33 \frac{f_{y b}}{227.7}\right) \frac{f_{y b}}{227.7} \text { if } \frac{f_{y b}}{458.8} \leq 1 \text { or } C_{3}=1.34 \text { if } \frac{f_{y b}}{458.85}>1 \\
& C_{4}=\left(1.15-0.15 \frac{r}{t}\right) \leq 1 \text { but not less than } 0.50 \\
& C_{\theta}=0.7+0.3(\phi / 90)^{2} \\
& \frac{1.07 R_{E d}}{\phi_{w} R_{w, R d}}+\frac{M_{E d}}{\phi_{b} M_{c, R d}} \leq 1.42 \\
& R_{W C-B D}=R_{E d}=1.327 /\left(\frac{1}{\phi_{w} R_{w, R d}}+\frac{L-s_{s L}}{4 \phi_{b} M_{C, R d}}\right) \\
& \leq \min \left\{F_{E d}, 4 M_{c, R d} /\left(L-s_{S L}\right)\right\}
\end{aligned}
$$

\section{Summary of the proposed web crippling resistance function for stainless steel cross-sections}

The investigation conducted by Bock et al. (2013) examined numerically the web crippling response of ferritic and austenitic stainless steel SHS, RHS and hat sections using the finite element software ABAQUS. In the study, the load cases under consideration were internal and external concentrated loads applied through one flange, IOF and EOF respectively. It is noteworthy that this load cases resemble the web crippling response of continuous spans where the local transverse force satisfy IOF loading (Category 2) at interior supports while EOF loading (Category 1 ) is given at the end of the member as shown in Fig. 1, where these forces are denoted as $\mathrm{s}_{\mathrm{sL}}$ for the former and $\mathrm{s}_{\mathrm{sa}}$ for the latter. The obtained models, which had been validated against existing experimental results conducted by Talja and Hradil (2011), were used to analyse key parameters influencing the web crippling resistance. Comparisons presented by Bock et al. (2013) with numerical and test data, highlighted the over conservative predictions of EN 1993-1-3 and showed that some modifications of the original formula given in the code could improve the predicted strength. Upon this observation, three main changes were proposed: the inclusion of the $1 \%$ proof strength $\sigma_{1.0}$ in order to consider the strain hardening of stainless steel, some adjustments of the corner radius and the bearing length influence, and three dimensionless coefficients $(\beta, \delta$ and $\xi)$ were added to obtain better fit with numerical data (see Table 1). The proposed resistance model is given by Eq. (16) where $\mathrm{k}=\delta \mathrm{r} / \mathrm{t}$ and $\mathrm{l}_{\mathrm{a}}=0.01 \mathrm{~s}_{\mathrm{s}}$ for EOF (or Category 1 ) while for IOF (or Category 2), $1_{\mathrm{a}}=2.2 \mathrm{~s}_{\mathrm{s}}$. Predictions by this proposed resistance model were observed to provide more accurate web crippling resistances than EN 1993-1-3 (2006) enabling a more efficient design. Furthermore, the expression was observed to be suitable for application to both types of stainless steel: austenitic and ferritic stainless steels. 

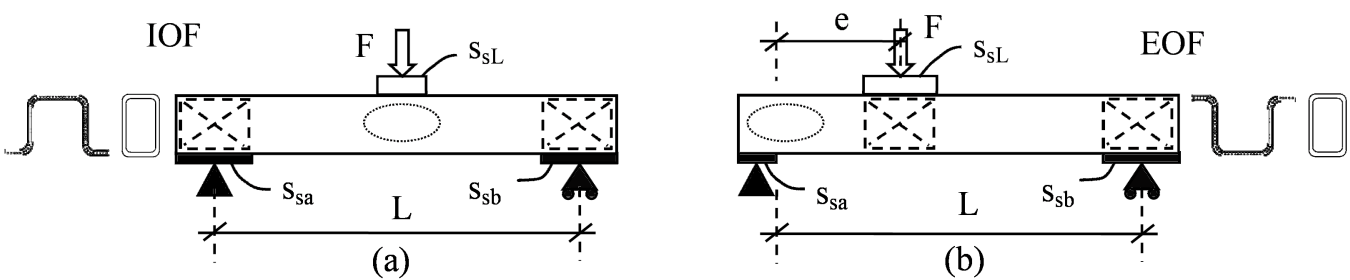

Fig. 1 Loading cases considered: (a) interior one-flange (IOF or Category 2) and (b) exterior one-flange (EOF or Category 1)

$$
R_{w, R d}=\alpha t^{2} \sqrt{\sigma_{0.2} E}\left(\xi \frac{\sigma_{1.0}}{E}\right)^{k} \sqrt{\frac{\beta t}{r}}\left(0.5+\sqrt{\frac{0.01_{a}}{t}}\right)\left(2.4+\left(\frac{\phi}{90}\right)^{2}\right) / \gamma_{M 1}
$$

Table 1. Dimensionless coefficient values

\begin{tabular}{lcccc}
\hline \multirow{2}{*}{ Coefficient } & \multicolumn{2}{c}{ Category 1 (EOF) } & \multicolumn{2}{c}{ Category 2 (IOF) } \\
& SHS/RHS & Hat sections & SHS/RHS & Hat sections \\
\hline$\alpha$ & 0.07 & 0.085 & 0.13 & 0.14 \\
$\beta$ & 2.14 & 1.65 & 0.59 & 0.81 \\
$\delta$ & 0.22 & 0.13 & 0.14 & 0.065 \\
$\xi$ & 2200 & 2275 & 2700 & 2000 \\
\hline
\end{tabular}

\section{Statistical analysis}

\subsection{Annex D of EN 1990}

When an alternative design rule is proposed, the resulting design model $r_{t}$ for the resistance function $g_{r t}\left(\underline{X}_{m}\right)$, where $\underline{X}_{m}$ refers to all basic variables (i.e. geometry, mechanical material properties and dimensionless coefficients) that affect the resistance at the relevant limit state, should be in accordance with the principles of EN 1990 (2002). Annex D of EN 1990 (2002) establishes the principles for design assisted by testing, where the reliability of the derived model is assesses on the basis of a statistical interpretation of available test data. The standard evaluation procedure given in Annex D of EN 1990 (2002) considers two methods to statistically evaluate a design model: Method a) by evaluating the characteristic value of the resistance function $r_{k}$; and Method b) by direct determination of the design value of the resistance function $r_{d}$. Hence, the partial safety factor can be obtained dividing the characteristic value by the design value as given by Eq. (17).

$\gamma_{M 1}=\frac{r_{k}}{r_{d}}$

Both methods are given in Annex D of EN 1990 (2002) as a number of discrete steps which are summarised in Table 2 . It is important to mention that the basic variables $X_{i}$ (related to material and geometry) for evaluating the design and characteristic resistance functions, $r_{d}$ and $r_{k}$ respectively, are based on different values. While the material mechanical properties are defined as nominal values $\left(\sigma_{0.2}\right.$ nom $)$, which could be understood as the minimum (characteristic) value to be satisfied after the steelmaking with an over-strength ratio $\mathrm{M}_{\text {osr }}$ (average difference between the true strength of the material and the value used in design), the nominal geometrical values are adopted as mean values with a certain fabrication tolerance. To statistically harmonise these discrepancies and use nominal values for all input parameters, EN 1990 introduces the nominal resistance function $r_{n}$ to correct the partial safety factor $\gamma_{M 1}$ into $\gamma_{M 1}^{*}$. The 
nominal value of this resistance function $r_{n}$ is determined evaluating the resistance function using the nominal values for the basic variables (i.e. measured value for the geometry and $\sigma_{0.2 \mathrm{nom}}=\sigma_{0.2} / \mathrm{M}_{\mathrm{osr}}$ for the material where $\sigma_{0.2}$ is the measured value of the $0.2 \%$ proof strength). Baddoo and Francis $(2012,2013)$ undertook a large collection of data from steel producers and manufacturers where the over-strength ratio $\mathrm{M}_{\mathrm{osr}}$ was found to be 1.3, 1.2 and 1.1 for austenitic, ferritic and duplex stainless steel, respectively. The transformed value of $\gamma_{M 1}^{*}$ is given by Eq. (18) and is used herein to statistically evaluate the proposed resistance function $r_{t}$ by Bock et al. (2013) (Eq. (19)) and existing design standards.

$$
\begin{aligned}
& \gamma_{M 1}^{*}=\frac{r_{k}}{r_{d}} \frac{r_{n}}{r_{k}}=\frac{r_{n}}{r_{d}} \\
& r_{t}=g_{r t}\left(\underline{X}_{m}\right)=\alpha t^{2} \sqrt{\sigma_{0.2} E}\left(\xi \frac{\sigma_{1.0}}{E}\right)^{k} \sqrt{\frac{\beta t}{r}}\left(0.5+\sqrt{\frac{0.01_{a}}{t}}\right)\left(2.4+\left(\frac{\phi}{90}\right)^{2}\right)
\end{aligned}
$$

\begin{tabular}{|c|c|c|}
\hline Step & Feature & Objective \\
\hline $\begin{array}{l}\text { 1. Develop a design } \\
\text { model }\end{array}$ & $r_{t}=g_{r t}\left(\underline{X}_{m}\right)$ & $\begin{array}{l}\text { Develop a design model for the theoretical } \\
\text { resistance } \mathrm{r}_{\mathrm{t}} \text { represented by the resistance function } \\
g_{r t}\left(\underline{X}_{m}\right) \text { and to consider all the basic variables } \mathrm{X}_{\mathrm{i}} \\
\text { through the vector } \underline{X}_{m}=\sum_{i=1}^{m} X_{i} \text {, where } \mathrm{m} \text { is the } \\
\text { number of the various basic variables (i.e. } \\
\text { geometry, material, coefficients) }\end{array}$ \\
\hline $\begin{array}{l}\text { 2. Compare } \\
\text { experimental (or } \\
\text { numerical) and } \\
\text { theoretical values }\end{array}$ & $\begin{array}{r}r_{e} \\
\text { (experimental } \\
\text { or numerical) }\end{array}$ & $\begin{array}{l}\text { See and study the deviation of all the } \\
\text { experimental (or numerical) } \mathrm{r}_{\mathrm{e}, \mathrm{i}} \text { and their } \\
\text { corresponding theoretical values } \mathrm{r}_{\mathrm{t}, \mathrm{i}} \text {. If the } \\
\text { resistance function is exact and complete, the } \\
\text { points will lie on the line } \theta=\pi / 4 \text {, but in practice } \\
\text { the points show some scatter. The vectors } \mathrm{r}_{\mathrm{e}, \mathrm{i}} \text { and } \\
\mathrm{r}_{\mathrm{e}, \mathrm{t}} \text { must have the same dimension } \mathrm{n} \text { (population } \\
\text { of data taken under consideration) }\end{array}$ \\
\hline
\end{tabular}

Table 2. Summary of the discrete steps

3. Estimate the mean value of the correction factor $b$

\begin{tabular}{|c|c|c|c|c|}
\hline $\begin{array}{l}\text { 5. Analyse } \\
\text { compatibility }\end{array}$ & Kolmogorov-Smirnov & & & $\begin{array}{l}\text { Test the normality of the distribution of the errors } \\
\delta_{\mathrm{i}}\end{array}$ \\
\hline \multirow{5}{*}{$\begin{array}{l}6 . \text { Define the } \\
\text { coefficients of } \\
\text { variation } \mathrm{V}_{\mathrm{X}, \mathrm{i}} \text { for the } \\
\text { basic variables } \mathrm{X}_{\mathrm{i}} \\
\text { (material and } \\
\text { geometry) }\end{array}$} & Paran & Mean $X_{i}$ & $V_{X, i}$ & \multirow{5}{*}{$\begin{array}{l}\text { These coefficients of variation } V_{X, i} \text { have been } \\
\text {-recently presented for stainless steel in Baddoo } \\
\text { and Francis (2012, 2013) after an extensive } \\
\text { statistical study of data collected from the } \\
\text { stainless steel suppliers and manufacturers }\end{array}$} \\
\hline & $\mathrm{M}_{\mathrm{osr}} \sigma_{0.2}$ for austenitic & $1.3 \sigma_{0.2, \mathrm{nom}}$ & 0.066 & \\
\hline & $\mathrm{M}_{\mathrm{osr}} \sigma_{0.2}$ for ferritic & $1.2 \sigma_{0.2, \mathrm{nom}}$ & 0.050 & \\
\hline & $\mathrm{M}_{\mathrm{osr}} \sigma_{0.2}$ for duplex & $1.1 \sigma_{0.2, \mathrm{nom}}$ & 0.049 & \\
\hline & Geometry & nominal value & 0.050 & \\
\hline
\end{tabular}

\begin{tabular}{lcc}
\hline $\begin{array}{l}\text { 4. Estimate the } \\
\text { coefficient of } \\
\text { variation } V_{\delta} \text { of the } \delta_{\mathrm{i}} \\
\text { error terms }\end{array}$ & $\delta_{i}=\frac{r_{e, i}}{b r_{t, i}}$ & $\bar{\Delta}=\frac{1}{n} \sum_{i=1}^{n} \Delta_{i}$ \\
& $\Delta_{i}=\ln \left(\delta_{i}\right)$ & $s_{\Delta}^{2}=\frac{1}{n-1} \sum_{i=1}^{n}\left(\Delta_{i}-\bar{\Delta}\right)^{2}$
\end{tabular}

Represent the probabilistic model of the resistance $\mathrm{r}$ in the format $r=b r_{t, i} \delta$, where $\mathrm{b}$ is the least squares best-fit to the slope and $\delta$ is the error term

Determine the error term $\delta_{\mathrm{i}}$ for each experimental (or numerical) value $r_{e, i}$ to estimate the coefficient of variation of the errors from the values of $\Delta_{i}, \bar{\Delta}$ and $s_{\Delta}^{2}$ through

$$
V_{\delta}=\sqrt{\exp \left(s_{\Delta}^{2}\right)-1}
$$




\begin{tabular}{|c|c|c|}
\hline Step & Feature & Objective \\
\hline $\begin{array}{l}\text { 7. Define the } \\
\text { combined } \\
\text { coefficient of } \\
\text { variation } V_{r}^{2}\end{array}$ & $\begin{array}{c}V_{r t}^{2}=\frac{\operatorname{var}\left[g_{r t}\left(X_{m}\right)\right]}{g_{r t}^{2}\left(\underline{X}_{m}\right)}=\frac{1}{g_{r t}^{2}\left(\underline{X}_{m}\right)} \sum_{i=1}^{j}\left[\frac{\partial g_{r t}}{\partial X_{i}} \cdot V_{X, i}\right]^{2} \\
V_{r}^{2}=V_{\delta}^{2}+V_{r t}^{2}+V_{F E M}^{2}\end{array}$ & $\begin{array}{l}\text { This term is considered to include all possible } \\
\text { deviations: errors }\left(V_{\delta}\right) \text {, resistance function }\left(V_{r t}^{2}\right) \\
\text { and the deviation of the numerical model }\left(V_{F E M}^{2}\right) \\
\text { proposed by Davaine (2005) given in sub-section } \\
4.3\end{array}$ \\
\hline $\begin{array}{l}\text { 8.a. Method a) } \\
\text { Definition of the } \\
\text { characteristic value }\end{array}$ & $\begin{array}{c}r_{k}=b C_{k} g_{r t}\left(X_{m}\right) \\
C_{k}=\exp \left(-k_{\infty} \alpha_{r t} Q_{r t}-k_{n} \alpha_{\delta} Q_{\delta}-0,5 Q^{2}\right)\end{array}$ & $\begin{array}{c}Q_{r t}=\sqrt{\ln \left(V_{r t}^{2}+1\right)} \quad Q_{\delta}=\sqrt{\ln \left(V_{\delta}^{2}+1\right)} \\
Q=\sqrt{\ln \left(V_{r}^{2}+1\right)}\end{array}$ \\
\hline $\begin{array}{l}\text { 8.b. Method b) } \\
\text { Definition of the } \\
\text { design value }\end{array}$ & $\begin{array}{c}r_{d}=b C_{d} g_{r t}\left(X_{m}\right) \\
C_{d}=\exp \left(-k_{d, \infty} \alpha_{r t} Q_{r t}-k_{d, n} \alpha_{\delta} Q_{\delta}-0,5 Q^{2}\right)\end{array}$ & $\begin{array}{l}\alpha_{r t}=\frac{Q_{r t}}{Q} \quad \alpha_{\delta}=\frac{Q_{\delta}}{Q} \\
k_{n} \text { and } k_{\infty} \text { are defined in Table D1 of EN } 1990 \\
\text { whereas } k_{d, n} \text { and } k_{d, \infty} \text { are given in Table D2. }\end{array}$ \\
\hline $\begin{array}{l}\text { 9. Partial safety } \\
\text { factor }\end{array}$ & $\gamma_{M 1}=\frac{r_{k}}{r_{d}}=\frac{C_{k}}{C_{d}}$ & $\begin{array}{l}\text { The partial safety factor is obtained dividing } r_{\mathrm{k}} \text { by } \\
\mathrm{r}_{\mathrm{d}}\end{array}$ \\
\hline $\begin{array}{l}\text { 10. Corrected } \\
\text { partial safety factor }\end{array}$ & $\gamma_{M 1}^{*}=\frac{r_{k}}{r_{d}} \frac{r_{n}}{r_{k}}=\frac{r_{n}}{r_{d}}$ & $\begin{array}{l}\text { To adapt the partial safety factor to better } \\
\text { statistical variations }\end{array}$ \\
\hline
\end{tabular}

\subsection{Adaptation of the procedure to a numerical database}

The original procedure given in Annex D of EN 1990 (2002) is intended to statistically evaluate resistance functions (design models) derived through the use of experimental data $r_{e}$ (experimental). Due to the fact that the statistical evaluation performed in this study is based on numerical results, $r_{e}$ (numerical), an additional term $V_{\text {FEM }}$ was considered for the combined coefficient of variation $V_{r}^{2}$ as given by Eq. (20).

$V_{r}^{2}=V_{\delta}^{2}+V_{r t}^{2}+V_{F E M}^{2}$

This $\mathrm{V}_{\mathrm{FEM}}$ term refers to the coefficient of variation of the numerical model and was proposed to be included in $V_{r}^{2}$ by Davaine (2005) to consider uncertainties and unfavourable deviations between the numerical model and the experimental data considered for its calibration; this approach has also been used by Gabeler (2009) and Chacón et al. (2012) in their studies on plate girders subjected to patch loading. The proposed process by Davaine (2005) to determine the value of $\mathrm{V}_{\mathrm{FEM}}$ is given in Eqs. (21)-(26) where $r_{e, i}$ are experimental values, $r_{F E M, i}$ are their corresponding numerical values predicted by the numerical model, $b_{\mathrm{FEM}}$ is the average ratio of experimental to numerical based on a least squares fit to the test data, $\delta_{\mathrm{FEM}, \mathrm{i}}$ is the error term for each numerical value, $\mathrm{n}_{\mathrm{FEM}}$ is the population of numerical analyses taken under consideration and $\mathrm{r}_{\mathrm{FEM}, \mathrm{i}}, \Delta_{\mathrm{FEM}, \mathrm{i}}, \bar{\Delta}_{F E M}$ and $s_{\triangle, F E M}^{2}$ are statistical parameters. Note that this notation resembles the one used to determine the coefficient of variation of the error $V_{\delta}$ (see Table 2).

$$
\begin{aligned}
b_{F E M} & =\frac{\sum r_{e, i} r_{F E M, i}}{\sum r_{F E M, i}^{2}} \\
\delta_{F E M, i} & =\frac{r_{e, i}}{b_{F E M} r_{F E M, i}} \\
\Delta_{F E M, i} & =\ln \left(\delta_{F E M, i}\right)
\end{aligned}
$$




$$
\begin{aligned}
& \bar{\Delta}_{F E M}=\frac{1}{n_{F E M}} \sum_{i=1}^{n_{F E M}} \ln \left(\delta_{F E M, i}\right) \\
& s_{\triangle, F E M}^{2}=\frac{1}{n_{F E M}-1} \sum_{i=1}^{n}\left(\Delta_{F E M, i}-\bar{\Delta}_{F E M}\right)^{2} \\
& V_{F E M}=\sqrt{\exp \left(s_{\triangle, F E M}^{2}\right)-1}
\end{aligned}
$$

\section{Numerical analyses}

\subsection{Available numerical database}

In order to conduct the statistical evaluation of the proposed resistance function (Eq (19)), the generated numerical data by Bock et al. (2013) was considered and split into sub-sets based on their load condition, cross-section geometry and material. Given the fact that most of the numerical analyses were performed on ferritic stainless steel crosssections and little numerical data for austenitic stainless steel was available, this latter database is expanded in the present paper on the basis of parametric studies by using the finite element package ABAQUS. Further details of the numerical analyses are given in the following sub-sections. Having complemented the original available numerical data, a total of 262 and 182 numerical results for ferritic and austenitic stainless, respectively, steel were involved in the statistical analysis. Details of the amount of numerical data considered in each sub-set are given in Table 3.

Table 3. Available numerical database

\begin{tabular}{llll}
\hline Load case & Cross-Section type & Ferritics & Austenitics \\
\multirow{2}{*}{ IOF } & SHS/RHS & 83 & 53 \\
& Hat sections & 74 & 64 \\
\multirow{2}{*}{ EOF } & SHS/RHS & 71 & 41 \\
& Hat sections & 34 & 24 \\
\hline
\end{tabular}

\subsection{Parametric study}

The additional numerical analyses of the simulations performed by using ABAQUS on austenitic stainless steel cross-sections with material mechanical properties given in Table 4 are described herein. The cross-sections considered were SHS, RHS and hat sections with the dimensions given in Table 5 with reference to symbols shown in Fig. 2. These cross-sections were modelled under IOF and EOF loading. Thicknesses of 2 $\mathrm{mm}$ and $4 \mathrm{~mm}$ for the SHS and RHS and $1 \mathrm{~mm}$ and $2 \mathrm{~mm}$ for the hat sections were considered. The length of all the specimens (L) remained constant at $500 \mathrm{~mm}$. The length of the supports $\left(\mathrm{s}_{\mathrm{sa}}\right.$ and $\mathrm{s}_{\mathrm{sb}}$ ) for the IOF loading was set to $50 \mathrm{~mm}$ while the bearing length through of which the load is applied $\left(\mathrm{s}_{\mathrm{SL}}\right)$ was $25 \mathrm{~mm}$. For the EOF loading, the length of the support that produces web crippling (end bearing support, $\mathrm{s}_{\mathrm{sa}}$ ) was $25 \mathrm{~mm}$ whereas for the further end support $\left(\mathrm{s}_{\mathrm{sb}}\right)$ was $50 \mathrm{~mm}$. The load was applied through a plate $\left(\mathrm{s}_{\mathrm{sL}}\right)$, which was $50 \mathrm{~mm}$ length, and the distance from its centre to the edge of the end bearing support (e) was $150 \mathrm{~mm}$. All these abovementioned parameters are depicted in Fig. 1. 4-point bending models were also performed on these geometries to determine the moment resistance of the cross-section $\mathrm{M}_{\mathrm{c}, \mathrm{Rd}}$ and study the combined bending and web crippling interaction effects for IOF loading (Eqs. 5 and 15). In these models, the load was applied through two plates of $50 \mathrm{~mm}$-wide placed at $1 / 3$ and $2 / 3$ of the total length which was set to $1000 \mathrm{~mm}$. Additional specimens were modelled for materials $\mathrm{A} 1^{*}$ and $\mathrm{A} 2 *$ to study the influence of various parameters on the web crippling strength, including: two more corner radii $\left(\mathrm{r}_{\mathrm{m}}=4 \mathrm{~mm}\right.$ and $5 \mathrm{~mm}$ for S5, S6, S7 
and S9 and $\mathrm{r}_{\mathrm{m}}=5 \mathrm{~mm}$ and $6 \mathrm{~mm}$ for S8); four more bearing lengths for IOF loading $\left(\mathrm{s}_{\mathrm{sL}}=40 \mathrm{~mm}, 50 \mathrm{~mm}, 75 \mathrm{~mm}\right.$ and $\left.100 \mathrm{~mm}\right)$; and four more end bearing lengths $\left(\mathrm{s}_{\mathrm{sa}}=40\right.$ $\mathrm{mm}, 50 \mathrm{~mm}, 75 \mathrm{~mm}$ and $100 \mathrm{~mm}$ ) and two plate lengths over which the load is applied $\left(\mathrm{s}_{\mathrm{sL}}=75 \mathrm{~mm}\right.$ and $\left.100 \mathrm{~mm}\right)$ for EOF loading. A total of 44 and 64 numerical analyses were performed on austenitic SHS/RHS and hat sections under IOF loading respectively, while for EOF loading the number of conducted numerical analyses were 31 and 24 for SHS/RHS and hat sections, respectively. Further details of the numerical model used herein are given in Bock et al. (2013) where a carefully validation against experimental results was also undertaken. Recall that the parametric study performed herein on austenitic stainless steel cross-section complements the numerical data reported in Bock et al. (2013) where more focus was given to the web crippling response of ferritic stainless steel cross-sections. The document also reports an assessment of the sensitivity of the numerical model to different key modelling parameters including initial imperfections and mesh studies as well as the influence of various geometries and material properties on the web crippling response.

Table 4. Material mechanical properties considered

\begin{tabular}{ccccccccc}
\hline Material & $\mathrm{E}(\mathrm{GPa})$ & $\sigma_{0.2}(\mathrm{MPa})$ & $\mathrm{n}$ & $\sigma_{1.0}(\mathrm{MPa})$ & $\sigma_{\mathrm{u}}(\mathrm{MPa})$ & $\mathrm{m}$ & $\varepsilon_{\mathrm{u}}$ & $\sigma_{\mathrm{u}} / \sigma_{0.2}$ \\
\hline $\mathrm{A} 1$ & 200 & 250 & 5 & 256 & 275 & 3 & 0.4 & 1.1 \\
$\mathrm{~A}{ }^{*}$ & 200 & 250 & 5 & 262.2 & 300 & 3 & 0.4 & 1.2 \\
$\mathrm{~A} 2$ & 200 & 250 & 5 & 275 & 350 & 3 & 0.4 & 1.4 \\
$\mathrm{~A} 2 *$ & 200 & 250 & 5 & 300 & 450 & 3 & 0.4 & 1.8 \\
\hline
\end{tabular}

Table 5. Basic cross-section geometries considered

\begin{tabular}{cccccc}
\hline Cross-section & Label & $\mathrm{b}(\mathrm{mm})$ & $\mathrm{h}_{\mathrm{w}}(\mathrm{mm})$ & $\mathrm{c}(\mathrm{mm})$ & $\mathrm{r}_{\mathrm{m}}(\mathrm{mm})$ \\
\hline SHS $70 \times 70 \times \mathrm{t}$ & S5 & 70 & 70 & - & 3 \\
RHS $60 \times 120 \times \mathrm{t}$ & S6 & 60 & 120 & - & 3 \\
Hat $60 \times 60 \times 20 \times \mathrm{t}$ & S7 & 60 & 60 & 20 & 3 \\
Hat $120 \times 120 \times 50 \times \mathrm{t}$ & S8 & 120 & 120 & 50 & 3 \\
Hat $60 \times 80 \times 25 \times \mathrm{t}$ & S9 & 60 & 80 & 25 & 3 \\
\hline
\end{tabular}

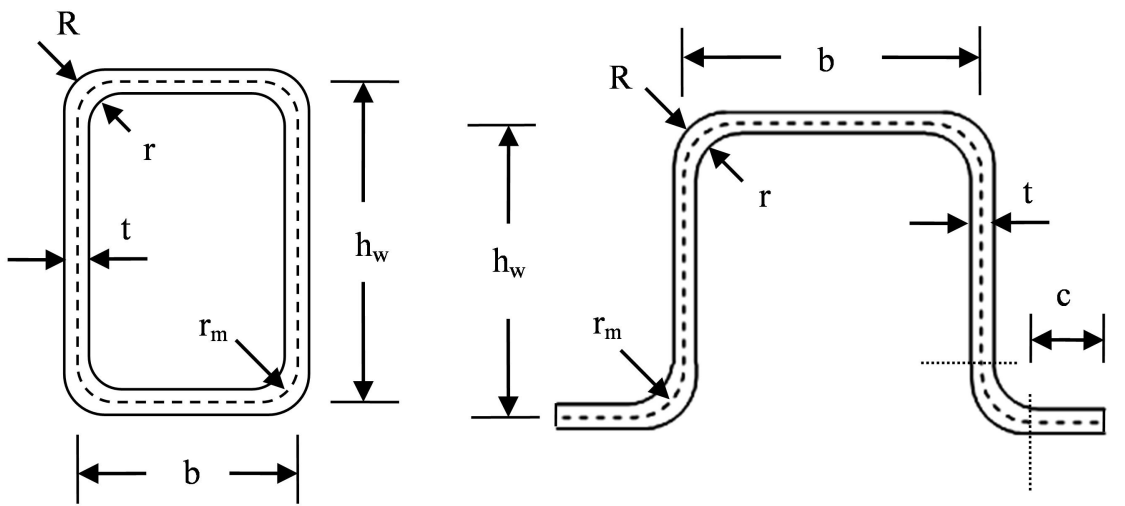

Fig. 2 Definition of symbols for the cross-sections

The obtained numerical results of this parametric study performed on austenitic stainless steel cross-sections are presented in Appendix A where all the specimens were labelled following the same criteria used by Bock et al. (2013) so that the austenitic counterpart result could be compared with the ferritic one. 


\section{Results of the statistical evaluation}

\subsection{General}

In this section, the obtained partial safety factors for the eight sub-sets of considered data ( 2 load conditions, 2 types of cross-section and 2 materials shown in Table 3 ) and key results for the steps summarised in Table 2 are analysed and used to assess the reliability of the proposed resistance function by Bock et al. (2013). The equations given in EN 1993-1-3 (2006) and SEI/ASCE 8-02 (2002) were also considered in this statistical analysis for comparison purposes.

\subsection{Estimation of $V_{\text {FEM }}$}

The coefficient of variation of the numerical model $\mathrm{V}_{\text {FEM }}$ was determined preceding the actual statistical analyses since, as mentioned earlier, the data under consideration was based on numerical results. To this end, the results from the validation of the numerical model given by Bock et al. (2013), where existing test performed by Gardner et al. (2006) and Talja and Hradil (2011) were collected and modelled by using ABAQUS, were considered to determine such parameter. The results are shown in Table 6 where $r_{e, i}$ and $r_{F E M, i}$ are the reported values in the corresponding documents for the experimental and numerical web crippling strength of the cross-section respectively, and $b_{\mathrm{FEM}}, \delta_{\mathrm{FEM}, \mathrm{i}}, \Delta_{\mathrm{FEM}, \mathrm{i}}, \bar{\Delta}_{\mathrm{FEM}}$ and $s_{\triangle, F E M}^{2}$ are key statistical parameters determined according to Eqs. (21)-(26).

Table 6. Determination of the $\mathrm{V}_{\mathrm{FEM}}$

\begin{tabular}{|c|c|c|c|c|c|c|c|c|c|}
\hline $\begin{array}{l}\text { Type } \\
\text { of } \\
\text { load }\end{array}$ & Specimen & $r_{e, i}(k N)$ & $\begin{array}{l}\mathrm{r}_{\mathrm{FEM}, \mathrm{i}} \\
(\mathrm{kN})\end{array}$ & $\mathrm{r}_{\mathrm{e}, \mathrm{i}} \mathrm{i} \mathrm{r}_{\mathrm{FEM}, \mathrm{i}}$ & $\mathrm{r}_{\mathrm{e}, \mathrm{i}} \mathrm{r}_{\mathrm{FEM}, \mathrm{i}}$ & $\mathrm{r}_{\mathrm{FEM}, \mathrm{i}^{2}}$ & $\delta_{\mathrm{FEM}, \mathrm{i}}$ & $\Delta_{\mathrm{FEM}, \mathrm{i}}$ & $\begin{array}{c}\left(\Delta_{\mathrm{FEM}, \mathrm{i}}\right. \\
\left.-\bar{\Delta}_{\mathrm{FEM}}\right)^{2}\end{array}$ \\
\hline \multirow{5}{*}{ EOF } & SHS ES & 25.76 & 35.36 & 0.73 & 910.9 & 1250.3 & 0.671 & -0.399 & 0.1241 \\
\hline & TH_10_ES ${ }^{\mathrm{a}}$ & 7.16 & 7.03 & 1.02 & 50.3 & 49.4 & 0.939 & -0.063 & 0.0003 \\
\hline & TH_15_ES ${ }^{\mathrm{a}}$ & 15.03 & 15.07 & 1.00 & 226.5 & 227.1 & 0.919 & -0.084 & 0.0015 \\
\hline & TH_20_ES ${ }^{\mathrm{a}}$ & 25.91 & 25.82 & 1.00 & 669.0 & 666.7 & 0.925 & -0.078 & 0.0010 \\
\hline & $\mathrm{TH}=30 \mathrm{ES}^{\mathrm{a}}$ & 42.06 & 39.93 & 1.05 & 1679.5 & 1594.4 & 0.971 & -0.030 & 0.0003 \\
\hline \multirow{8}{*}{ IOF } & SHS_IS ${ }^{\mathrm{a}}$ & 43.92 & 37.02 & 1.19 & 1625.9 & 1370.5 & 1.093 & 0.089 & 0.0183 \\
\hline & SHS $100 \times 100 \times 3^{b}$ & 107.10 & 101.18 & 1.06 & 10836.4 & 10237.4 & 0.975 & -0.025 & 0.0005 \\
\hline & SHS_120×80×3 & 108.30 & 96.42 & 1.12 & 10442.3 & 9296.8 & 1.035 & 0.034 & 0.0065 \\
\hline & RHS_ $140 \times 60 \times 3^{b}$ & 107.50 & 95.69 & 1.12 & 10286.7 & 9156.6 & 1.035 & 0.035 & 0.0065 \\
\hline & TH_10_IS ${ }^{\mathrm{a}}$ & 10.00 & 9.75 & 1.03 & 97.5 & 95.1 & 0.945 & -0.056 & 0.0001 \\
\hline & TH_15_IS ${ }^{\mathrm{a}}$ & 20.73 & 19.59 & 1.06 & 406.1 & 383.8 & 0.975 & -0.025 & 0.0004 \\
\hline & TH_20_IS ${ }^{\mathrm{a}}$ & 34.84 & 32.41 & 1.07 & 1129.2 & 1050.4 & 0.991 & -0.009 & 0.0013 \\
\hline & $\mathrm{TH}_{-}^{-} 30_{-}^{-} \mathrm{IS}^{\mathrm{a}}$ & 55.01 & 50.09 & 1.10 & 2755.5 & 2509.0 & 1.012 & 0.012 & 0.0034 \\
\hline \multirow{2}{*}{\multicolumn{2}{|c|}{$\begin{array}{l}{ }^{\mathrm{a}} \text { Talja and Hradil (2011) } \\
{ }^{\mathrm{b}} \text { Gardner et al. (2006) }\end{array}$}} & & & & \multicolumn{2}{|c|}{$b_{\mathrm{FEM}}=1.085$} & \multicolumn{2}{|c|}{$\bar{\Delta}_{F E M}=-0.046$} & $\begin{array}{l}s_{\triangle, F E M}^{2} \\
=0.014\end{array}$ \\
\hline & & & & & \multicolumn{5}{|c|}{$V_{F E M}=0.117$} \\
\hline
\end{tabular}

\subsection{Resulting partial safety factors}

The obtained partial safety factors from the statistical evaluations are presented herein. The structural design guidance for stainless steels, the EN 1993-1-4 (2006), employs a partial safety factor $\gamma_{M 1}^{*}$ of 1.1. Hence, partial safety factors falling below this value of 1.1 reflect that the resistance function is reliable. Above 1.1, the design approach is deemed to be unsafe thereby requiring a recalibration so that the safety level is satisfied. Tables 7 and 8 show key results of the statistical evaluation for IOF and EOF loading respectively, while Figs. 3 and 4 show the numerical resistances $r_{e}$ plotted against the predicted ones $r_{t}$ for IOF and EOF loading respectively, where the least squares best-fit to the slope $\mathrm{b}$ is also given (Step 2 from Table 2). Table 9 show key statistical values 
concerning mean predictions and coefficient of variation (COV) of the three design approaches relative to the numerical results for IOF loading while for EOF loading, these are given in Table 10. From the results for IOF loading given in Table 7, it can be observed that the proposed resistance function by Bock et al. (2013) satisfies the safety level recommended in EN 1993-1-4 (2006) for all sets of data. Note also that this proposal provides higher partial safety factors for ferritic stainless steel than the austenitics reflecting that the former ones are designed more efficiently. EN 1993-1-3 (2006) yields similar partial safety factors for hat sections, though the safety level for SHS and RHS is not satisfied. This is associated with the inaccuracy of the approach to predict web crippling strength for such cross-sections, as is highlighted in Fig. 3(a) and (c) where it is observed that EN 1993-1-3 (2006) over-estimates the resistance of some specimens. Recall that EN 1993-1-3 (2006) does not make allowance for SHS and RHS, and the approach recommended by Talja and Salmi (1995) was used herein. The assessment for SEI/ASCE 8-02 (2002) shows that this approach is not suitable for the material and cross-sections considered in the present study since the predicted web crippling capacity is too optimistic (see Fig. 3).

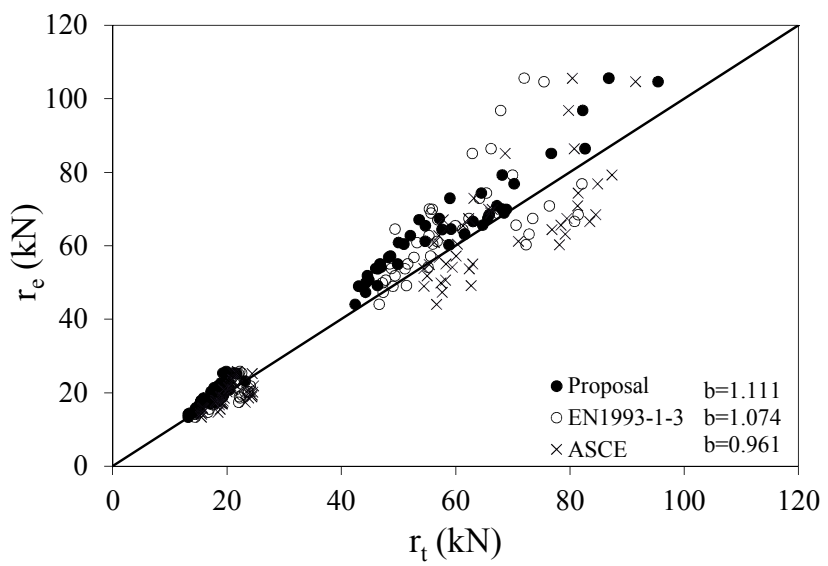

(a) Ferritic SHS/RHS

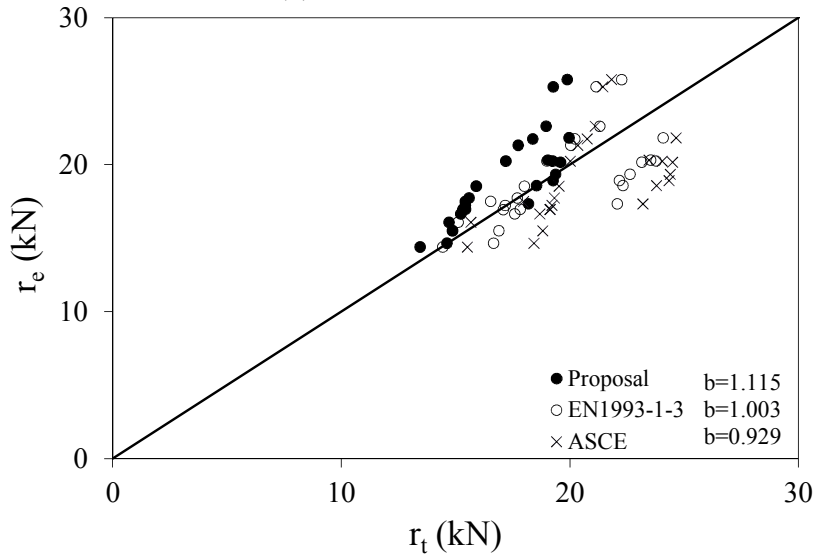

(c) Austenitic SHS/RHS

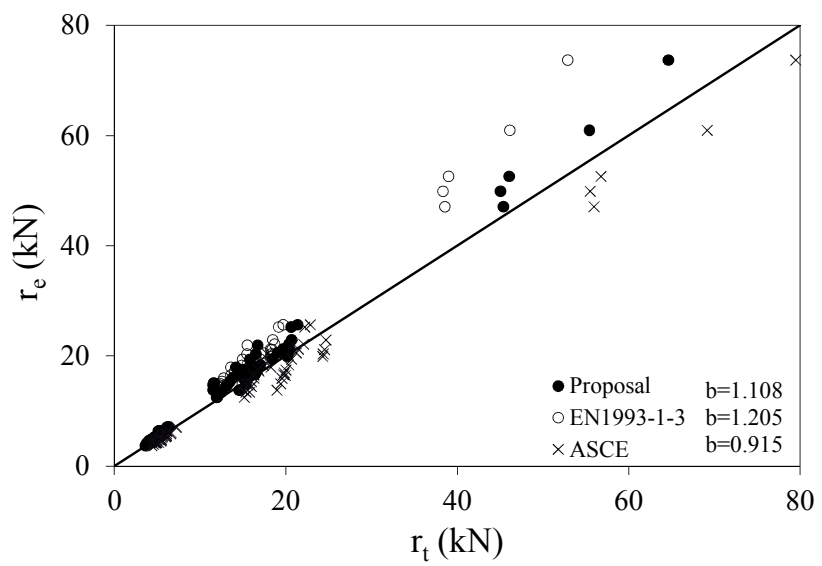

(b) Ferritic hat sections

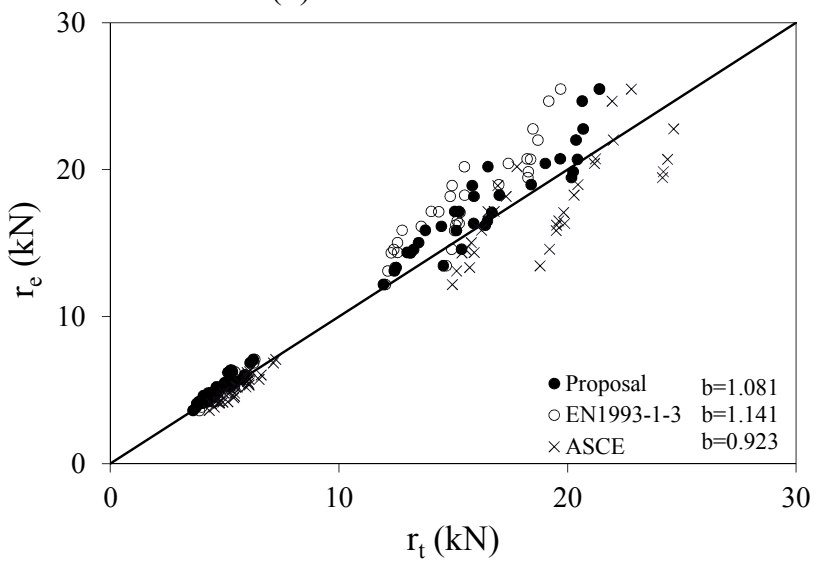

(d) Austenitic hat sections

Fig. 3 Comparison of numerical loads $r_{e}$ and predicted resistances $r_{t}$ by EN 1993-1-3 (2006), SEI/ASCE 8-02 (2002) and proposal for IOF loading 
Table 7. Summary of statistical evaluation of various approaches for IOF loading

\begin{tabular}{lllcccc}
\hline Material & Cross-section & Design approach & $\mathrm{V}_{\delta}$ & $\mathrm{V}_{\mathrm{r}}$ & $\gamma_{M 1}$ & $\gamma_{M 1}^{*}$ \\
\hline \multirow{4}{*}{ Ferritic } & \multirow{3}{*}{ SHS/RHS } & EN 1993-1-3 & 0.132 & 0.036 & 1.194 & 1.147 \\
\cline { 3 - 7 } & & ASCE & 0.131 & 0.036 & 1.193 & 1.280 \\
\cline { 3 - 7 } & \multirow{3}{*}{ Hat sections } & Proposal & 0.070 & 0.024 & 1.099 & 0.928 \\
\cline { 3 - 7 } & \multirow{3}{*}{ Austenitic } & ASCE & 0.090 & 0.027 & 1.126 & 1.188 \\
\cline { 3 - 7 } & \multirow{3}{*}{ SHS/RHS } & Proposal & 0.068 & 0.023 & 1.098 & 0.928 \\
\cline { 3 - 7 } & & EN 1993-1-3 & 0.122 & 0.036 & 1.194 & 1.131 \\
\cline { 3 - 7 } & \multirow{3}{*}{ Hat sections } & ASCE & 0.125 & 0.036 & 1.199 & 1.232 \\
\cline { 3 - 7 } & & Proposal & 0.073 & 0.026 & 1.119 & 0.888 \\
\hline & & EN 1993-1-3 & 0.090 & 0.029 & 1.141 & 0.904 \\
\cline { 3 - 7 } & & ASCE & 0.095 & 0.030 & 1.149 & 1.134 \\
\cline { 3 - 7 } & & Proposal & 0.062 & 0.025 & 1.105 & 0.892 \\
\hline
\end{tabular}

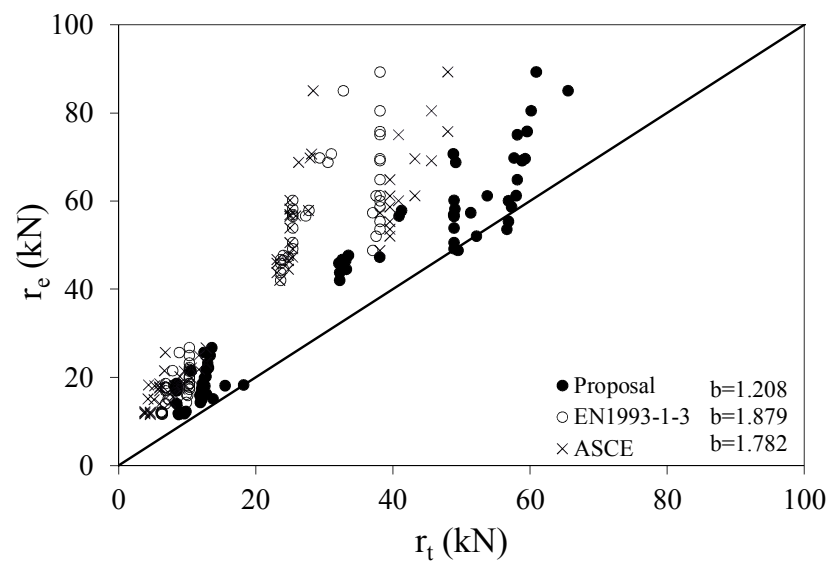

(a) Ferritic SHS/RHS

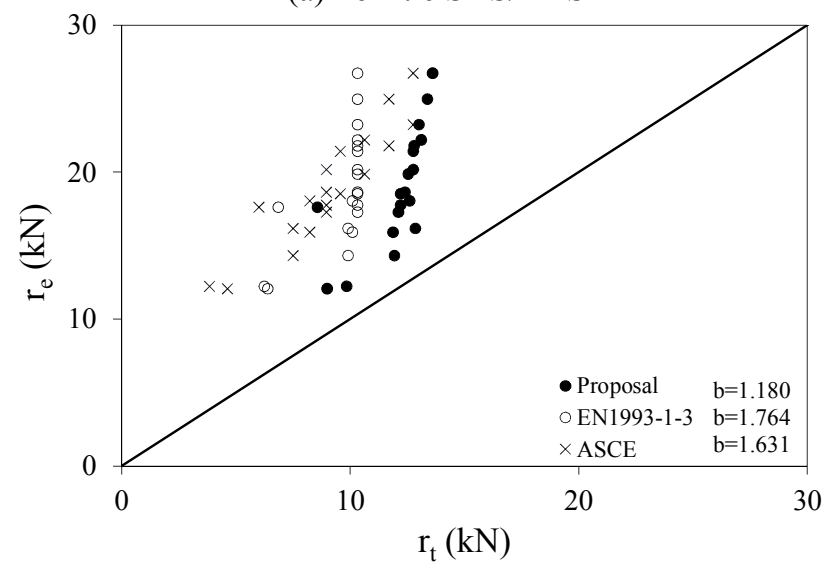

(c) Austenitic SHS/RHS

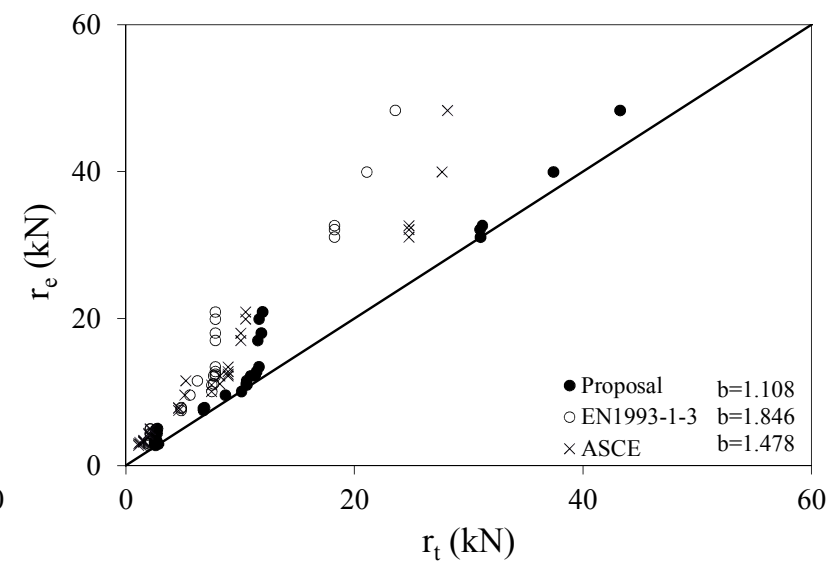

(b) Ferritic hat sections

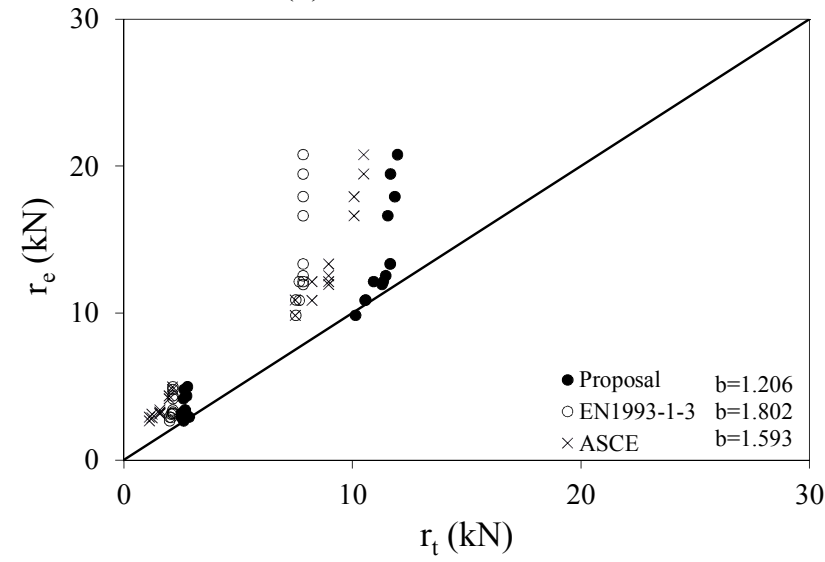

(d) Austenitic hat sections

Fig. 4 Comparison of numerical loads $r_{e}$ and predicted resistances $r_{t}$ by EN 1993-1-3 (2006), SEI/ASCE 8-02 (2002) and proposal for EOF loading 
Table 8. Summary of statistical evaluation of various approaches for EOF loading

\begin{tabular}{|c|c|c|c|c|c|c|}
\hline Material & Cross-section & Design approach & $\mathrm{V}_{\delta}$ & $\mathrm{V}_{\mathrm{r}}$ & $\gamma_{M 1}$ & $\gamma_{M 1}^{*}$ \\
\hline \multirow{6}{*}{ Ferritic } & \multirow{3}{*}{ SHS/RHS } & EN 1993-1-3 & 0.177 & 0.050 & 1.282 & 0.763 \\
\hline & & ASCE & 0.273 & 0.094 & 1.488 & 1.120 \\
\hline & & Proposal & 0.216 & 0.066 & 1.361 & 1.355 \\
\hline & \multirow{3}{*}{ Hat sections } & EN 1993-1-3 & 0.185 & 0.053 & 1.323 & 0.819 \\
\hline & & ASCE & 0.226 & 0.070 & 1.419 & 1.188 \\
\hline & & Proposal & 0.190 & 0.055 & 1.334 & 1.388 \\
\hline \multirow{6}{*}{ Austenitic } & \multirow{3}{*}{ SHS/RHS } & EN 1993-1-3 & 0.171 & 0.050 & 1.294 & 0.760 \\
\hline & & ASCE & 0.208 & 0.064 & 1.373 & 0.933 \\
\hline & & Proposal & 0.202 & 0.062 & 1.360 & 1.263 \\
\hline & \multirow{3}{*}{ Hat sections } & EN 1993-1-3 & 0.217 & 0.068 & 1.436 & 0.907 \\
\hline & & ASCE & 0.230 & 0.074 & 1.470 & 1.076 \\
\hline & & Proposal & 0.206 & 0.064 & 1.408 & 1.244 \\
\hline
\end{tabular}

Regarding the results for EOF loading, which are given in Table 8, it is observed that the proposed resistance function by Bock et al. (2013) yields unreliable predictions for the recommended value $\gamma_{M 1}^{*}$ of 1.1 given in EN 1993-1-4 (2006). Similar results are observed for the approach given in SEI/ASCE 8-02 (2002) when is applied to ferritic stainless steels, however, the safety level for the austenitics is satisfied. Unlike the results for IOF loading, where some approaches over-estimated web crippling capacities, the unsatisfactory partial safety factors obtained for EOF loading are associated with the high scatter (COV) provided by the actual design approach (see Table 10). Note that, as shown in Fig. 4, the three design methods provide safe values, though the web crippling resistances are overly underestimated as shown the mean prediction given in Table 10. This is also highlighted in the results for the statistical evaluation of EN 1993-1-3 (2006) where all partial safety factors are far below 1.1, but satisfying the safety level. Hence, on the basis of these observations, it is concluded that a revised expression of the proposed resistance function is required for EOF loading. This is conducted in the following section.

Table 9. Key statistical values of the comparison for IOF loading

\begin{tabular}{|c|c|c|c|c|c|}
\hline Material & Cross-section & Design approa & & Mean & $\mathrm{COV}$ \\
\hline \multirow{6}{*}{ Ferritic } & \multirow{3}{*}{ SHS/RHS } & EN 1993-1-3 & $\mathrm{r}_{\mathrm{e}} / \mathrm{r}_{\mathrm{t}}$ & 1.048 & 0.133 \\
\hline & & ASCE & $\mathrm{r}_{\mathrm{e}} / \mathrm{r}_{\mathrm{t}}$ & 0.958 & 0.132 \\
\hline & & Proposal & $\mathrm{r}_{\mathrm{e}} / \mathrm{r}_{\mathrm{t}}$ & 1.109 & 0.070 \\
\hline & \multirow{3}{*}{ Hat sections } & EN 1993-1-3 & $\mathrm{r}_{\mathrm{e}} / \mathrm{r}_{\mathrm{t}}$ & 1.135 & 0.102 \\
\hline & & ASCE & $\mathrm{r}_{\mathrm{e}} / \mathrm{r}_{\mathrm{t}}$ & 0.931 & 0.090 \\
\hline & & Proposal & $\mathrm{r}_{\mathrm{e}} / \mathrm{r}_{\mathrm{t}}$ & 1.101 & 0.069 \\
\hline \multirow{6}{*}{ Austenitic } & \multirow{3}{*}{ SHS/RHS } & EN 1993-1-3 & $\mathrm{r}_{\mathrm{e}} / \mathrm{r}_{\mathrm{t}}$ & 1.008 & 0.120 \\
\hline & & ASCE & $\mathrm{r}_{\mathrm{e}} / \mathrm{r}_{\mathrm{t}}$ & 0.938 & 0.125 \\
\hline & & Proposal & $\mathrm{r}_{\mathrm{e}} / \mathrm{r}_{\mathrm{t}}$ & 1.117 & 0.072 \\
\hline & \multirow{3}{*}{ Hat sections } & EN 1993-1-3 & $\mathrm{r}_{\mathrm{e}} / \mathrm{r}_{\mathrm{t}}$ & 1.090 & 0.090 \\
\hline & & ASCE & $\mathrm{r}_{\mathrm{e}} / \mathrm{r}_{\mathrm{t}}$ & 0.921 & 0.095 \\
\hline & & Proposal & $\mathrm{r}_{\mathrm{e}} / \mathrm{r}_{\mathrm{t}}$ & 1.078 & 0.062 \\
\hline
\end{tabular}


Table 10. Key statistical values of the comparison for EOF loading

\begin{tabular}{|c|c|c|c|c|c|}
\hline Material & Cross-section & Design approa & & Mean & $\mathrm{COV}$ \\
\hline \multirow{6}{*}{ Ferritic } & \multirow{3}{*}{ SHS/RHS } & EN 1993-1-3 & $r_{e} / r_{t}$ & 2.007 & 0.173 \\
\hline & & ASCE & $\mathrm{r}_{\mathrm{e}} / \mathrm{r}_{\mathrm{t}}$ & 2.218 & 0.278 \\
\hline & & Proposal & $\mathrm{r}_{\mathrm{e}} / \mathrm{r}_{\mathrm{t}}$ & 1.386 & 0.225 \\
\hline & \multirow{3}{*}{ Hat sections } & EN 1993-1-3 & $\mathrm{r}_{\mathrm{e}} / \mathrm{r}_{\mathrm{t}}$ & 1.763 & 0.193 \\
\hline & & ASCE & $\mathrm{r}_{\mathrm{e}} / \mathrm{r}_{\mathrm{t}}$ & 1.822 & 0.219 \\
\hline & & Proposal & $\mathrm{r}_{\mathrm{e}} / \mathrm{r}_{\mathrm{t}}$ & 1.241 & 0.203 \\
\hline \multirow{6}{*}{ Austenitic } & \multirow{3}{*}{ SHS/RHS } & EN 1993-1-3 & $\mathrm{r}_{\mathrm{e}} / \mathrm{r}_{\mathrm{t}}$ & 1.874 & 0.168 \\
\hline & & ASCE & $\mathrm{r}_{\mathrm{e}} / \mathrm{r}_{\mathrm{t}}$ & 1.906 & 0.211 \\
\hline & & Proposal & $\mathrm{r}_{\mathrm{e}} / \mathrm{r}_{\mathrm{t}}$ & 1.358 & 0.206 \\
\hline & \multirow{3}{*}{ Hat sections } & EN 1993-1-3 & $\mathrm{r}_{\mathrm{e}} / \mathrm{r}_{\mathrm{t}}$ & 1.742 & 0.225 \\
\hline & & ASCE & $\mathrm{r}_{\mathrm{e}} / \mathrm{r}_{\mathrm{t}}$ & 1.883 & 0.216 \\
\hline & & Proposal & $\mathrm{r}_{\mathrm{e}} / \mathrm{r}_{\mathrm{t}}$ & 1.287 & 0.209 \\
\hline
\end{tabular}

\subsection{Recalibration of the proposed resistance function}

Having concluded that the proposed resistance function for EOF loading requires further adjustment, a revised value for the new non-dimensional coefficient $\alpha$ was sought. This was achieved by setting the corrected partial safety factor $\gamma_{M 1}^{*}$ for the most restrictive set of data (i.e. ferritic stainless steel SHS and RHS) to the required safety level of 1.1 and limiting the number of decimals of the coefficient $\alpha$. The coefficients $\beta$, $\delta$ and $\xi$ were kept since non-significant improvements were observed. The resulting value for $\alpha$ is given in Table 11 together with the coefficients for IOF loading. The results of the statistical evaluation of the recalibrated resistance function for EOF loading are shown in Table 12 where previous resulting partial safety factors for EN 1993-1-3 (2006) and SEI/ASCE 8-02 (2002) are also given. The updated results for the comparison between the numerical resistances $r_{e}$ and the predicted ones $r_{t}$, including the least squares best-fit to the slope parameter b (Step 2 from Table 2), and for the key statistical values concerning mean predictions and coefficient of variation (COV) of the three design approaches relative to the numerical results are given in Fig. 5 and Table 13, respectively. The results show that the recalibrated resistance function satisfies the safety level set out in EN 1993-1-4 (2006). Besides, as it has been observed for IOF loading, higher partial safety factors are achieved for ferritic stainless steels than for the austenitics reflecting that the former ones are designed more efficiently.

Table 11. Dimensionless coefficient values after recalibration

\begin{tabular}{lcccc}
\hline \multirow{2}{*}{ Coefficient } & \multicolumn{2}{c}{ Category 1 (EOF) } & \multicolumn{2}{c}{ Category 2 (IOF) } \\
& SHS/RHS & Hat & SHS/RHS & Hat \\
\hline$\alpha$ & 0.057 & 0.067 & 0.13 & 0.14 \\
$\beta$ & 2.14 & 1.65 & 0.59 & 0.81 \\
$\delta$ & 0.22 & 0.13 & 0.14 & 0.065 \\
$\xi$ & 2200 & 2275 & 2700 & 2000 \\
\hline
\end{tabular}




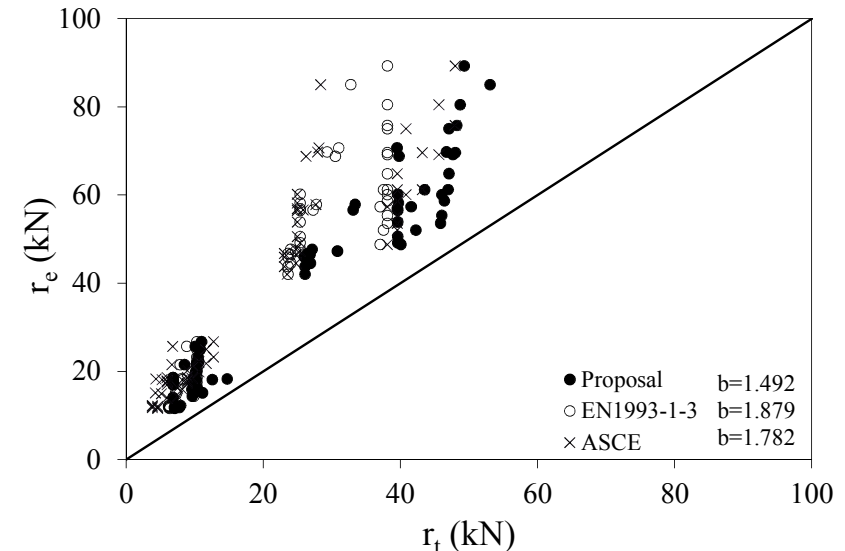

(a) Ferritic SHS/RHS

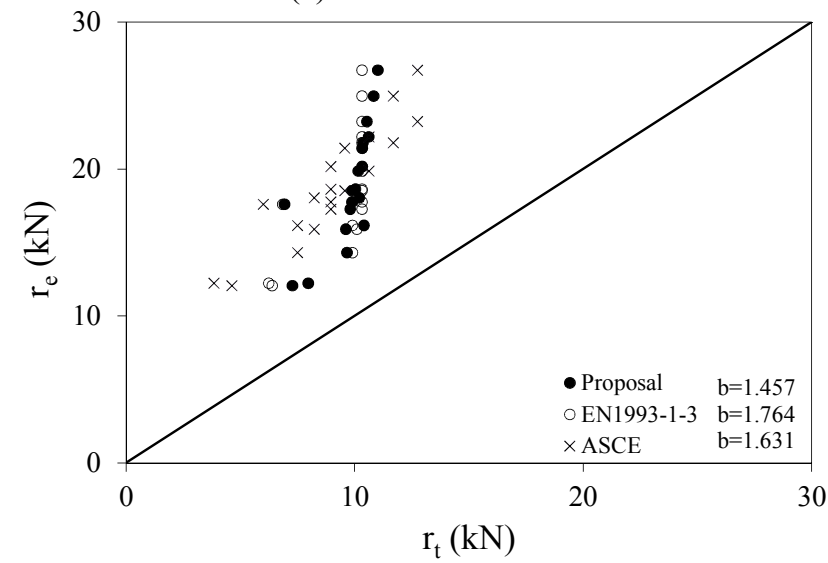

(c) Austenitic SHS/RHS

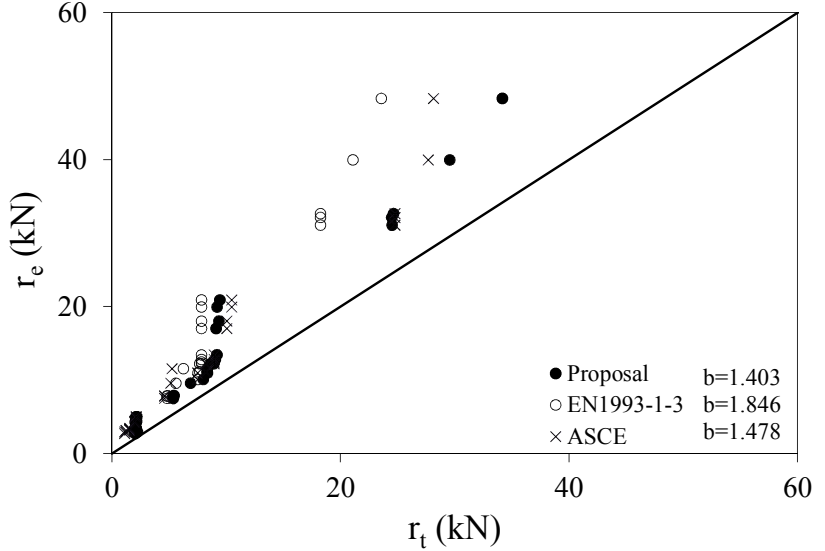

(b) Ferritic hat sections

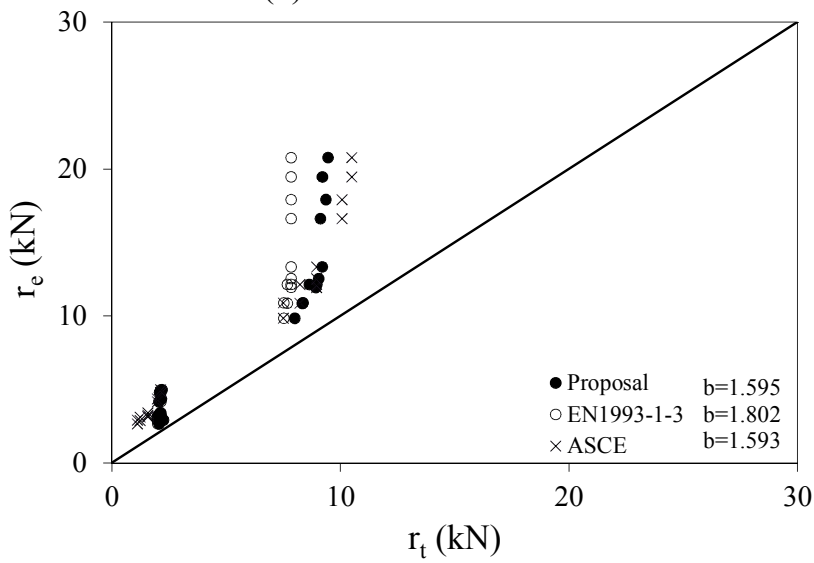

(d) Austenitic hat sections

Fig. 5 Comparison of numerical loads $r_{e}$ and predicted resistances $r_{t}$ by EN 1993-1-3

(2006), SEI/ASCE 8-02 (2002) and proposal for EOF loading after recalibration

Table 12. Partial safety factors for EOF load condition after recalibration

\begin{tabular}{|c|c|c|c|c|c|c|}
\hline Material & Cross-section & Design approach & $\mathrm{V}_{\delta}$ & $\mathrm{V}_{\mathrm{r}}$ & $\gamma_{M 1}$ & $\gamma_{M 1}^{*}$ \\
\hline \multirow{6}{*}{ Ferritic } & \multirow{3}{*}{ SHS/RHS } & EN 1993-1-3 & 0.177 & 0.050 & 1.282 & 0.763 \\
\hline & & ASCE & 0.273 & 0.094 & 1.488 & 1.120 \\
\hline & & Proposal & 0.216 & 0.066 & 1.361 & 1.098 \\
\hline & \multirow{3}{*}{ Hat sections } & EN 1993-1-3 & 0.185 & 0.053 & 1.323 & 0.819 \\
\hline & & ASCE & 0.226 & 0.070 & 1.419 & 1.188 \\
\hline & & Proposal & 0.190 & 0.055 & 1.334 & 1.097 \\
\hline \multirow{6}{*}{ Austenitic } & \multirow{3}{*}{ SHS/RHS } & EN 1993-1-3 & 0.171 & 0.050 & 1.294 & 0.760 \\
\hline & & ASCE & 0.208 & 0.064 & 1.373 & 0.933 \\
\hline & & Proposal & 0.202 & 0.062 & 1.360 & 1.023 \\
\hline & \multirow{3}{*}{ Hat sections } & EN 1993-1-3 & 0.217 & 0.068 & 1.436 & 0.907 \\
\hline & & ASCE & 0.230 & 0.074 & 1.470 & 1.076 \\
\hline & & Proposal & 0.206 & 0.064 & 1.408 & 0.983 \\
\hline
\end{tabular}


Table 13. Key statistical values of the comparison for the EOF loading after recalibration

\begin{tabular}{|c|c|c|c|c|c|}
\hline Material & Cross-section & Design appro & & Mean & $\mathrm{COV}$ \\
\hline \multirow{6}{*}{ Ferritics } & \multirow{3}{*}{ SHS/RHS } & EN 1993-1-3 & $\mathrm{r}_{\mathrm{e}} / \mathrm{r}_{\mathrm{t}}$ & 2.007 & 0.173 \\
\hline & & ASCE & $\mathrm{r}_{\mathrm{e}} / \mathrm{r}_{\mathrm{t}}$ & 2.218 & 0.278 \\
\hline & & Proposal & $\mathrm{r}_{\mathrm{e}} / \mathrm{r}_{\mathrm{t}}$ & 1.711 & 0.225 \\
\hline & \multirow{3}{*}{ Hat sections } & EN 1993-1-3 & $\mathrm{r}_{\mathrm{e}} / \mathrm{r}_{\mathrm{t}}$ & 1.763 & 0.193 \\
\hline & & ASCE & $\mathrm{r}_{\mathrm{e}} / \mathrm{r}_{\mathrm{t}}$ & 1.822 & 0.219 \\
\hline & & Proposal & $\mathrm{r}_{\mathrm{e}} / \mathrm{r}_{\mathrm{t}}$ & 1.571 & 0.203 \\
\hline \multirow{6}{*}{ Austenitics } & \multirow{3}{*}{ SHS/RHS } & EN 1993-1-3 & $\mathrm{r}_{\mathrm{e}} / \mathrm{r}_{\mathrm{t}}$ & 1.874 & 0.168 \\
\hline & & ASCE & $\mathrm{r}_{\mathrm{e}} / \mathrm{r}_{\mathrm{t}}$ & 1.906 & 0.211 \\
\hline & & Proposal & $\mathrm{r}_{\mathrm{e}} / \mathrm{r}_{\mathrm{t}}$ & 1.676 & 0.202 \\
\hline & \multirow{3}{*}{ Hat sections } & EN 1993-1-3 & $r_{e} / r_{t}$ & 1.742 & 0.225 \\
\hline & & ASCE & $\mathrm{r}_{\mathrm{e}} / \mathrm{r}_{\mathrm{t}}$ & 1.883 & 0.216 \\
\hline & & Proposal & $\mathrm{r}_{\mathrm{e}} / \mathrm{r}_{\mathrm{t}}$ & 1.629 & 0.209 \\
\hline
\end{tabular}

\section{Validation of the revised design equation with experimental results}

The predictions of the proposed formulation by Bock et al. (2013) and given in Eq. (16) with revised non-dimensional coefficients from Table 11 are compared with existing test results on various stainless steel grades including high strength austenitic and duplex stainless steels (Zhou and Young (2007a, 2007b and 2007c)), austenitic stainless steels (Talja and Salmi (1995) and Gardner et al. (2006)) and ferritic stainless steels (Talja and Hradil (2011)). Capacity predictions according to EN 1993-1-3 (2006) and SEI/ASCE 8-02 (2002) are also determined. The comparisons for both load cases are given in Fig. 6 on the basis of the experimental to predicted ratio $r_{e} / r_{t}$ where it is observed that the recalibrated resistance function (proposal) achieves a reduction of mean prediction with similar scatter compared to existing design guidance, in line with the observations outlined in sub-sections 6.3 and 6.4 for the numerical data. Key statistical values concerning mean predictions and COV relative to the tests are given in Table 14 for the various sets of data.

Table 14. Statistical results of the ratio $r_{e} / r_{t}$ based on experimental results

\begin{tabular}{|c|c|c|c|c|c|}
\hline Load case & Cross-section & Design appro & & Mean & $\mathrm{COV}$ \\
\hline \multirow{6}{*}{ IOF } & \multirow{3}{*}{ SHS/RHS } & EN 1993-1-3 & $r_{\mathrm{e}} / \mathrm{r}_{\mathrm{t}}$ & 1.544 & 0.179 \\
\hline & & ASCE & $\mathrm{r}_{\mathrm{e}} / \mathrm{r}_{\mathrm{t}}$ & 1.404 & 0.204 \\
\hline & & Proposal & $\mathrm{r}_{\mathrm{e}} / \mathrm{r}_{\mathrm{t}}$ & 1.486 & 0.186 \\
\hline & \multirow{3}{*}{ Hat sections } & EN 1993-1-3 & $r_{e} / r_{t}$ & 1.584 & 0.051 \\
\hline & & ASCE & $\mathrm{r}_{\mathrm{e}} / \mathrm{r}_{\mathrm{t}}$ & 1.208 & 0.081 \\
\hline & & Proposal & $\mathrm{r}_{\mathrm{e}} / \mathrm{r}_{\mathrm{t}}$ & 1.194 & 0.079 \\
\hline \multirow{6}{*}{ EOF } & \multirow{3}{*}{ SHS/RHS } & EN 1993-1-3 & $\mathrm{r}_{\mathrm{e}} / \mathrm{r}_{\mathrm{t}}$ & 2.590 & 0.250 \\
\hline & & ASCE & $\mathrm{r}_{\mathrm{e}} / \mathrm{r}_{\mathrm{t}}$ & 2.884 & 0.224 \\
\hline & & Proposal & $\mathrm{r}_{\mathrm{e}} / \mathrm{r}_{\mathrm{t}}$ & 1.724 & 0.328 \\
\hline & \multirow{3}{*}{ Hat sections } & EN 1993-1-3 & $\mathrm{r}_{\mathrm{e}} / \mathrm{r}_{\mathrm{t}}$ & 2.572 & 0.027 \\
\hline & & ASCE & $\mathrm{r}_{\mathrm{e}} / \mathrm{r}_{\mathrm{t}}$ & 2.073 & 0.110 \\
\hline & & Proposal & $\mathrm{r}_{\mathrm{e}} / \mathrm{r}_{\mathrm{t}}$ & 1.694 & 0.139 \\
\hline
\end{tabular}




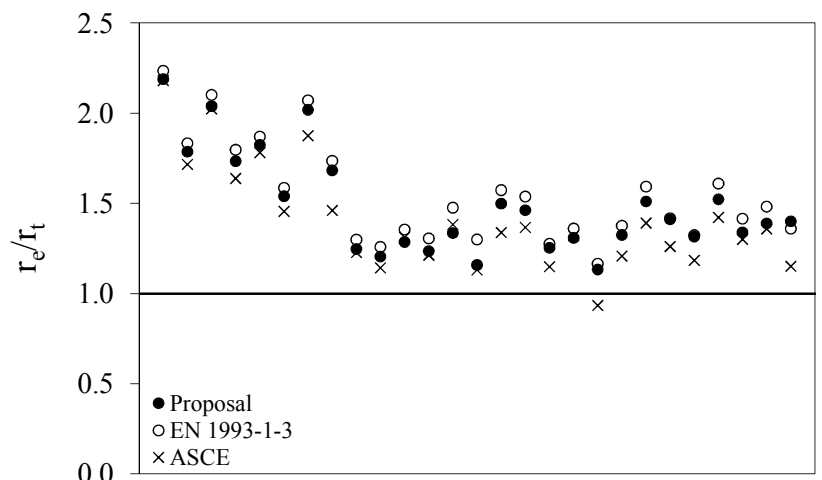

(a) SHS/RHS under IOF loading

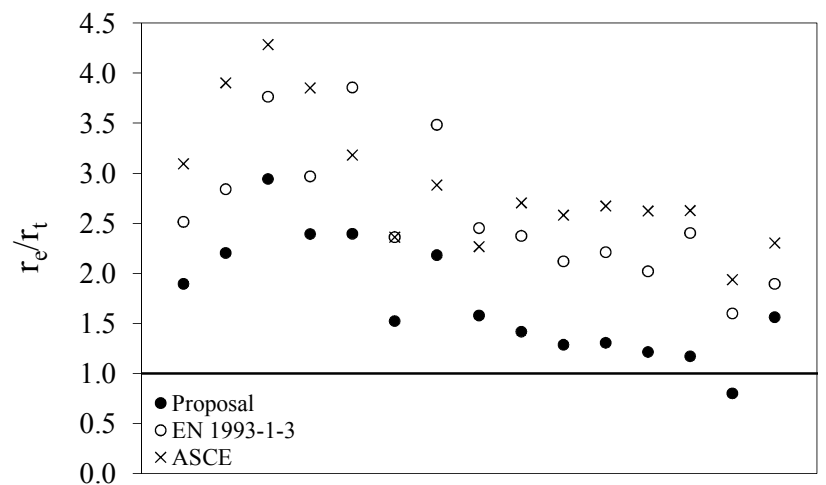

(c) SHS/RHS under EOF loading

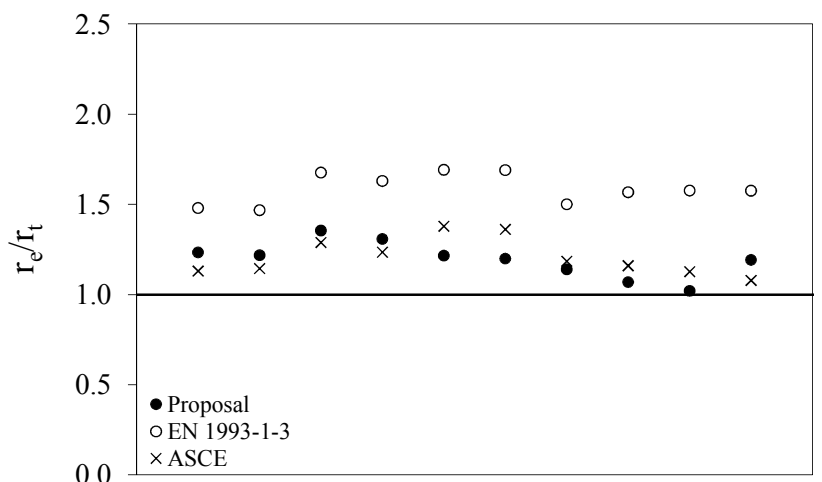

(b) Hat sections under IOF loading

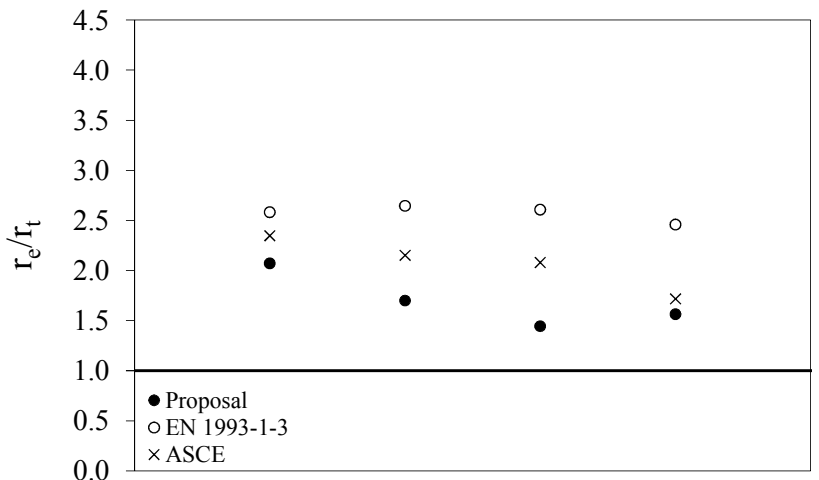

(d) Hat sections under EOF loading

Fig. 6 Comparison between the revised resistance function and existing provisions

\section{Conclusions}

A statistical evaluation of a proposed resistance model for web crippling design of stainless steel cross-sections under IOF and EOF loading by Bock et al. (2013) has been performed according to Annex D of EN 1990 (2002) to determine its level of reliability. Existing design provisions given in EN 1993-1-3 (2006) and SEI/ASCE 8-02 (2002) were also considered for comparison purposes. To this end, parametric studies on austenitic stainless steel were conducted herein to complement the existing numerical data which was considered to derive the proposed resistance model. The available numerical data was split into various sub-sets according to load case (IOF and EOF loading), cross-section geometry (SHS/RHS and hat sections) and material (austenitic and ferritic stainless steel) upon which the assessment of the resulting partial safety factors was based on.

The results show that the proposed resistance function satisfies the safety level recommended in EN 1993-1-4 (2006) for IOF loading, but required a readjustment for EOF loading to ensure reliable predictions. A new value for the non-dimensional coefficient $\alpha$ has been proposed. Regarding the assessment of the reliability of existing provisions, SEI/ASCE 8-02 (2002) was observed to be only appropriate for the design of the austenitic set of data under EOF loading generated herein while EN 1993-1-3 (2006) yielded satisfactory results for both load cases, though for IOF loading, the required safety level was not achieved for SHS and RHS.

Predicted web crippling resistances by EN 1993-1-3 (2006), SEI/ASCE 8-02 (2002) and the revised resistance function of numerical data and existing test results on various 
stainless steel grades showed that the latter provides more accurate predictions enabling a more efficient design for both types of load cases.

Building on the observations regarding the material effect on the partial safety factor and the good agreement achieved between ultimate capacity predictions and existing test results, it is speculated that the proposed formula is also applicable to duplex stainless steel because their stress-tress behaviour lays between the respective values for austenitic and ferritic grades but a formal validation is required.

\section{Acknowledgments}

The research leading to these results has received funding from the European Community's Research Fund for Coal and Steel (RFCS) under Grant Agreement No. RFSR-CT-2010-00026, Structural Applications for Ferritic Stainless Steels and from Ministerio de Ciencia e Innovación to the Project BIA2010-11876-E "Acciones complementarias". The first author would like to acknowledge the financial support provided by the Secretaria d'Universitats i de Recerca del Departament d'Economia i Coneixement de la Generalitat de Catalunya i del Fons Social Europeu. The authors gratefully acknowledge the scholarship provided by AGAUR to Mr Mirada. 


\section{Appendix A}

Tables A1-A4 present the capacity predictions according to EN 1993-1-3 (2006), SEI/ASCE 8-02 (2002) and proposed resistance model (proposal) of the numerical models generated herein. In these tables, $R_{u, n u m}$ is the numerical web crippling resistance of the cross-section, $\mathrm{M}_{\mathrm{c} \text {,num }}$ is the numerical bending moment resistance obtained in the 4-point bending model, $\mathrm{R}_{\mathrm{w}, \mathrm{Rd}}$ is the predicted value for the web crippling resistance and $\mathrm{R}_{\mathrm{WC}-\mathrm{BD}}$ is the combined web crippling and bending strength. All partial safety factors were set to unity to enable a direct comparison.

Specimens were labelled to easily identify load case, material, cross-section and thickness as well as corner radius and bearing length. The first three letters define the load case, where IOF refers to interior one-flange loading and EOF to exterior oneflange loading. The following notation describes the material type (A1, A1*, A2, A2*). The following letter and first number defines the section (S5 to S9). And finally, the value of the thickness (either $1 \mathrm{~mm}$ or $2 \mathrm{~mm}$ for hat sections and either $2 \mathrm{~mm}$ or $4 \mathrm{~mm}$ for SHS/RHS). Additional numbers were added when the corner radius or the bearing length that produces crippling $\left(\mathrm{ss}_{\mathrm{L}}\right.$ and $\mathrm{ss}_{\mathrm{a}}$ for IOF and EOF loading respectively, with their corresponding values) are varied and the number two is attached when the previously number refers to the variation of the plate length that applies the load $\left(\mathrm{s}_{\mathrm{sL}}\right)$ for EOF loading. The same labels were used by Bock et al. (2013) for ferritic stainless steel cross-sections and were adopted herein so that the austenitic counterpart could be compared. 
Table A1. Numerical and predicted resistances for SHS/RHS under IOF loading

\begin{tabular}{|c|c|c|c|c|c|c|c|c|}
\hline \multirow{2}{*}{ Specimen } & \multicolumn{2}{|c|}{ Numerical result } & \multicolumn{2}{|c|}{ EN1993-1-3 } & \multicolumn{2}{|c|}{ SEI/ASCE 8-02 } & \multicolumn{2}{|c|}{ Proposal } \\
\hline & $\begin{array}{l}\mathrm{R}_{\mathrm{u}, \text { num }} \\
(\mathrm{kN})\end{array}$ & $\begin{array}{l}\mathrm{M}_{\mathrm{c} \text { num }} \\
(\mathrm{kNm})\end{array}$ & $\begin{array}{l}\mathrm{R}_{\mathrm{w}, \mathrm{Rd}} \\
(\mathrm{kN})\end{array}$ & $\begin{array}{l}\mathrm{R}_{\mathrm{WC}-\mathrm{BD}} \\
(\mathrm{kN})\end{array}$ & $\begin{array}{l}\mathrm{R}_{\mathrm{w}, \mathrm{Rd}} \\
(\mathrm{kN})\end{array}$ & $\begin{array}{l}\mathrm{R}_{\mathrm{WC}-\mathrm{BD}} \\
(\mathrm{kN})\end{array}$ & $\begin{array}{l}\mathrm{R}_{\mathrm{w}, \mathrm{Rd}} \\
(\mathrm{kN})\end{array}$ & $\begin{array}{l}\mathrm{R}_{\mathrm{WC}-\mathrm{BD}} \\
(\mathrm{kN})\end{array}$ \\
\hline IOF A1S52 & 16.94 & 3.72 & 25.32 & 17.09 & 22.42 & 19.13 & 20.84 & 15.32 \\
\hline IOF A1S62 & 18.91 & 7.40 & 25.32 & 22.17 & 21.61 & 24.34 & 20.84 & 19.27 \\
\hline IOF A1*S52 & 17.22 & 3.76 & 25.32 & 17.18 & 22.42 & 19.22 & 20.95 & 15.43 \\
\hline IOF $\mathrm{A} 1 * \mathrm{~S} 524$ & 15.50 & 3.72 & 24.77 & 16.90 & 21.73 & 18.82 & 19.82 & 14.87 \\
\hline IOF A $1 *$ S525 & 14.65 & 3.695 & 24.29 & 16.67 & 21.04 & 18.43 & 19.37 & 14.63 \\
\hline $\mathrm{A} 1 * \mathrm{~S} 5250$ & 20.24 & 3.76 & 30.76 & 19.00 & 24.23 & 20.02 & 25.39 & 17.20 \\
\hline IOF A1*S5275 & 21.74 & 3.76 & 35.04 & 20.22 & 26.03 & 20.76 & 28.80 & 18.38 \\
\hline IOF A $1 * S 52100$ & 25.29 & 3.76 & 38.73 & 21.15 & 27.84 & 21.44 & 31.67 & 19.28 \\
\hline $\mathrm{IOF} \quad \mathrm{A} 1 * \mathrm{~S} 62$ & 19.34 & 7.46 & 25.99 & 22.63 & 21.61 & 24.40 & 20.95 & 19.38 \\
\hline $\mathrm{A} 1 * \mathrm{~S} 624$ & 18.57 & 7.38 & 25.60 & 22.32 & 20.95 & 23.79 & 19.82 & 18.55 \\
\hline $\mathrm{A} 1 * \mathrm{~S} 625$ & 17.33 & 7.33 & 25.27 & 22.07 & 20.28 & 23.20 & 19.37 & 18.20 \\
\hline IOF A2S52 & 17.73 & 3.80 & 26.52 & 17.70 & 22.42 & 19.33 & 21.16 & 15.59 \\
\hline IOF A2S62 & 20.16 & 7.56 & 26.70 & 23.15 & 21.61 & 24.49 & 21.16 & 19.59 \\
\hline IOF $\mathrm{A} 2 * \mathrm{~S} 52$ & 18.53 & 3.89 & 26.88 & 18.02 & 22.42 & 19.53 & 21.55 & 15.91 \\
\hline IOF A2*S524 & 16.96 & 3.86 & 26.48 & 17.83 & 21.73 & 19.14 & 20.58 & 15.44 \\
\hline $\mathrm{IOF} \quad \mathrm{A} 2 * \mathrm{~S} 525$ & 16.64 & 3.81 & 26.14 & 17.59 & 21.04 & 18.69 & 20.30 & 15.23 \\
\hline $\mathrm{IOF} \quad \mathrm{A} 2 * \mathrm{~S} 5250$ & 21.31 & 3.89 & 33.12 & 20.05 & 24.23 & 20.35 & 26.12 & 17.74 \\
\hline IOF $\quad A 2 * S 5275$ & 22.61 & 3.89 & 37.73 & 21.31 & 26.03 & 21.11 & 29.62 & 18.96 \\
\hline IOF A $2 * \mathrm{~S} 52100$ & 25.78 & 3.89 & 41.72 & 22.27 & 27.84 & 21.82 & 32.58 & 19.89 \\
\hline $\mathrm{IOF} \quad \mathrm{A} 2 * \mathrm{~S} 62$ & 21.82 & 7.72 & 28.01 & 24.09 & 21.61 & 24.65 & 21.55 & 19.97 \\
\hline IOF $\mathrm{A} 2 *$ S64 & 20.24 & 7.65 & 27.59 & 23.77 & 20.95 & 24.04 & 20.58 & 19.25 \\
\hline IOF $\mathrm{A} 2 * \mathrm{~S} 65$ & 20.30 & 7.63 & 27.24 & 23.54 & 20.28 & 23.47 & 20.30 & 19.04 \\
\hline IOF A1S54 & 53.81 & 7.92 & 101.61 & 48.79 & 90.99 & 54.48 & 87.99 & 46.06 \\
\hline IOF A1S64 & 65.58 & 15.75 & 102.32 & 70.58 & 89.39 & 78.43 & 87.99 & 64.76 \\
\hline $\mathrm{IOF} \quad \mathrm{A} 1 * \mathrm{~S} 54$ & 54.85 & 8.14 & 103.04 & 49.89 & 90.99 & 55.42 & 88.21 & 46.84 \\
\hline IOF A $1 *$ S544 & 51.79 & 8.06 & 102.24 & 49.41 & 90.99 & 55.05 & 79.85 & 44.58 \\
\hline $\mathrm{A} 1 * \mathrm{~S} 545$ & 48.94 & 7.99 & 101.6 & 49.06 & 89.63 & 54.47 & 74.65 & 43.05 \\
\hline $\mathrm{A} 1 * \mathrm{~S} 5450$ & 60.83 & 8.14 & 123.28 & 53.28 & 94.81 & 56.27 & 103.77 & 50.03 \\
\hline $\mathrm{A} 1 * \mathrm{~S} 5475$ & 62.71 & 8.14 & 138.1 & 55.33 & 98.62 & 57.09 & 115.71 & 52.10 \\
\hline IOF $\mathrm{A} 1 * \mathrm{~S} 54100$ & 67.07 & 8.14 & 150.91 & 56.88 & 102.4 & 57.86 & 125.77 & 53.65 \\
\hline A1*S64 & 67.40 & 16.23 & 107.47 & 73.49 & 89.39 & 79.50 & 88.21 & 65.65 \\
\hline $\mathrm{A} 1 * \mathrm{~S} 644$ & 63.13 & 16.085 & 106.64 & 72.89 & 89.39 & 79.18 & 79.85 & 61.59 \\
\hline $\mathrm{A} 1 * \mathrm{~S} 645$ & 60.25 & 15.93 & 105.99 & 72.33 & 88.05 & 78.19 & 74.65 & 58.85 \\
\hline A2S54 & 56.81 & 8.56 & 109.77 & 52.72 & 90.99 & 57.15 & 88.65 & 48.30 \\
\hline IOF A2S64 & 70.84 & 17.09 & 110.55 & 76.41 & 89.39 & 81.34 & 88.65 & 67.23 \\
\hline $\mathrm{IOF} \quad \mathrm{A} 2 * \mathrm{~S} 54$ & 60.44 & 9.37 & 111.34 & 55.99 & 90.99 & 60.31 & 89.47 & 50.97 \\
\hline $\mathrm{A} 2 * \mathrm{~S} 544$ & 57.13 & 9.32 & 110.49 & 55.64 & 90.99 & 60.12 & 81.37 & 48.63 \\
\hline IOF $\quad$ A $2 *$ S5 545 & 54.12 & 9.23 & 109.82 & 55.20 & 89.63 & 59.43 & 76.43 & 46.95 \\
\hline $\mathrm{A} 2 * \mathrm{~S} 5450$ & 65.43 & 9.37 & 133.25 & 59.95 & 94.81 & 61.33 & 105.25 & 54.71 \\
\hline IOF $\quad$ A $2 * S 5475$ & 67.35 & 9.37 & 149.29 & 62.36 & 98.62 & 62.30 & 117.35 & 57.17 \\
\hline $\mathrm{IOF} \quad \mathrm{A} 2 * \mathrm{~S} 54100$ & 72.89 & 9.37 & 163.16 & 64.19 & 102.44 & 63.22 & 127.56 & 59.01 \\
\hline $\mathrm{A} 2 * \mathrm{~S} 64$ & 76.84 & 18.90 & 116.2 & 82.13 & 89.39 & 84.87 & 89.47 & 70.26 \\
\hline $\mathrm{A} 2 * \mathrm{~S} 644$ & 68.43 & 18.72 & 115.32 & 81.44 & 89.39 & 84.54 & 81.37 & 65.91 \\
\hline IOF $\quad$ A $2 * S 645$ & 66.55 & 18.55 & 114.62 & 80.83 & 88.05 & 83.46 & 76.43 & 63.05 \\
\hline
\end{tabular}


Table A2. Numerical and predicted resistances for hat sections under IOF loading

\begin{tabular}{|c|c|c|c|c|c|c|c|c|}
\hline \multirow[b]{2}{*}{ Specimen } & \multicolumn{2}{|c|}{ Numerical result } & \multicolumn{2}{|c|}{ EN1993-1-3 } & \multicolumn{2}{|c|}{ SEI/ASCE 8-02 } & \multicolumn{2}{|c|}{ Proposal } \\
\hline & $\begin{array}{l}\mathrm{R}_{\mathrm{u}, \text { num }} \\
(\mathrm{kN})\end{array}$ & $\begin{array}{l}\mathrm{M}_{\mathrm{c}, \text { num }} \\
(\mathrm{kNm})\end{array}$ & $\begin{array}{l}\mathrm{R}_{\mathrm{w}, \mathrm{Rd}} \\
(\mathrm{kN})\end{array}$ & $\begin{array}{c}\mathrm{R}_{\mathrm{WC}-\mathrm{BD}} \\
(\mathrm{kN})\end{array}$ & $\begin{array}{l}\mathrm{R}_{\mathrm{w}, \mathrm{Rd}} \\
(\mathrm{kN})\end{array}$ & $\begin{array}{c}\mathrm{R}_{\mathrm{WC}-\mathrm{BD}} \\
(\mathrm{kN})\end{array}$ & $\begin{array}{l}\mathrm{R}_{\mathrm{w}, \mathrm{Rd}} \\
(\mathrm{kN})\end{array}$ & $\begin{array}{c}\mathrm{R}_{\mathrm{WC}-\mathrm{BD}} \\
(\mathrm{kN})\end{array}$ \\
\hline $\begin{array}{ll}\text { IOF } & \text { A1S71 }\end{array}$ & 4.11 & 0.98 & 5.52 & 4.09 & 5.30 & 4.75 & 5.22 & 3.91 \\
\hline IOF A1S81 & 5.35 & 2.53 & 5.52 & 5.45 & 4.82 & 6.06 & 5.22 & 5.19 \\
\hline IOF A1S91 & 4.48 & 1.42 & 5.52 & 4.67 & 5.14 & 5.39 & 5.22 & 4.47 \\
\hline IOF $\quad \mathrm{A} 1 * \mathrm{~S} 71$ & 4.15 & 0.99 & 5.52 & 4.10 & 5.30 & 4.77 & 5.24 & 3.94 \\
\hline IOF $\mathrm{A} 1 * \mathrm{~S} 714$ & 3.84 & 0.97 & 5.34 & 3.99 & 4.94 & 4.55 & 4.83 & 3.72 \\
\hline IOF $\mathrm{A} 1 * \mathrm{~S} 715$ & 3.61 & 0.96 & 5.18 & 3.90 & 4.57 & 4.32 & 4.60 & 3.59 \\
\hline $\mathrm{IOF} \quad \mathrm{A} 1 * \mathrm{~S} 7150$ & 4.76 & 0.99 & 6.86 & 4.64 & 6.09 & 5.14 & 6.54 & 4.47 \\
\hline IOF A1*S7175 & 5.22 & 0.99 & 7.89 & 4.99 & 7.10 & 5.56 & 7.53 & 4.82 \\
\hline IOF $\mathrm{A} 1 * \mathrm{~S} 71100$ & 6.19 & 0.99 & 8.75 & 5.26 & 8.34 & 5.99 & 8.37 & 5.08 \\
\hline IOF $\mathrm{A} 1 * \mathrm{~S} 81$ & 5.46 & 2.50 & 5.52 & 5.43 & 4.82 & 6.05 & 5.24 & 5.19 \\
\hline IOF $\quad A 1 * S 91$ & 4.58 & 1.44 & 5.52 & 4.70 & 5.14 & 5.42 & 5.24 & 4.50 \\
\hline IOF $\mathrm{A} 1 * \mathrm{~S} 914$ & 4.21 & 1.41 & 5.34 & 4.56 & 4.79 & 5.14 & 4.83 & 4.23 \\
\hline IOF A1*S915 & 4.18 & 1.44 & 5.18 & 4.50 & 4.44 & 4.92 & 4.60 & 4.11 \\
\hline IOF A1*S9150 & 5.21 & 1.44 & 6.86 & 5.42 & 5.90 & 5.93 & 6.54 & 5.21 \\
\hline IOF A1*S9175 & 5.73 & 1.44 & 7.89 & 5.91 & 6.89 & 6.51 & 7.53 & 5.69 \\
\hline IOF $A 1 * S 91100$ & 6.85 & 1.44 & 8.75 & 6.28 & 8.09 & 7.13 & 8.37 & 6.06 \\
\hline IOF A2S71 & 4.29 & 1.00 & 5.52 & 4.12 & 5.30 & 4.80 & 5.29 & 3.98 \\
\hline IOF A2S81 & 5.75 & 2.53 & 5.52 & 5.44 & 4.82 & 6.06 & 5.29 & 5.24 \\
\hline IOF A2S91 & 4.78 & 1.45 & 5.52 & 4.71 & 5.14 & 5.44 & 5.29 & 4.54 \\
\hline IOF $\quad$ A $2 *$ S7 1 & 4.62 & 1.03 & 5.52 & 4.14 & 5.30 & 4.85 & 5.38 & 4.06 \\
\hline IOF $\quad$ A $2 * S 714$ & 4.23 & 1.02 & 5.34 & 4.04 & 4.94 & 4.64 & 5.00 & 3.88 \\
\hline $\mathrm{IOF} \quad \mathrm{A} 2 * \mathrm{~S} 715$ & 4.09 & 1.01 & 5.18 & 3.96 & 4.57 & 4.42 & 4.81 & 3.77 \\
\hline IOF $\quad$ A $2 * S 7150$ & 5.06 & 1.03 & 6.86 & 4.69 & 6.09 & 5.24 & 6.71 & 4.62 \\
\hline IOF $\quad$ A $2 * S 7175$ & 5.49 & 1.03 & 7.89 & 5.04 & 7.10 & 5.67 & 7.73 & 4.98 \\
\hline IOF $\quad \mathrm{A} 2 * \mathrm{~S} 71100$ & 6.35 & 1.03 & 8.75 & 5.31 & 8.34 & 6.12 & 8.59 & 5.25 \\
\hline $\mathrm{IOF} \quad \mathrm{A} 2 * \mathrm{~S} 81$ & 6.24 & 2.58 & 5.52 & 5.45 & 4.82 & 6.09 & 5.38 & 5.33 \\
\hline IOF A2*S91 & 5.20 & 1.49 & 5.52 & 4.72 & 5.14 & 5.49 & 5.38 & 4.63 \\
\hline IOF $\quad$ A $2 * S 914$ & 4.81 & 1.48 & 5.34 & 4.61 & 4.79 & 5.22 & 5.00 & 4.40 \\
\hline IOF A2*S915 & 4.80 & 1.48 & 5.18 & 4.52 & 4.44 & 4.96 & 4.81 & 4.28 \\
\hline IOF A2*S9150 & 5.59 & 1.49 & 6.86 & 5.45 & 5.90 & 6.00 & 6.71 & 5.36 \\
\hline IOF $\quad$ A2*S9175 & 6.02 & 1.49 & 7.89 & 5.94 & 6.89 & 6.60 & 7.73 & 5.86 \\
\hline IOF $\mathrm{A} 2 * \mathrm{~S} 91100$ & 7.08 & 1.49 & 8.75 & 6.32 & 8.09 & 7.24 & 8.59 & 6.24 \\
\hline IOF A1S72 & 14.34 & 2.44 & 19.41 & 12.29 & 22.59 & 15.39 & 22.22 & 12.98 \\
\hline IOF A1S82 & 19.45 & 7.22 & 19.41 & 18.26 & 21.61 & 24.16 & 22.22 & 20.06 \\
\hline IOF A1S92 & 16.21 & 3.92 & 19.41 & 15.11 & 22.26 & 19.52 & 22.22 & 16.25 \\
\hline IOF $\quad A 1 * S 72$ & 14.57 & 2.48 & 19.41 & 12.40 & 22.59 & 15.54 & 22.27 & 13.11 \\
\hline IOF $\mathrm{A} 1 * \mathrm{~S} 724$ & 13.10 & 2.43 & 18.99 & 12.14 & 21.89 & 15.15 & 19.90 & 12.29 \\
\hline IOF $\quad$ A1*S725 & 12.18 & 2.43 & 18.62 & 12.03 & 21.19 & 14.96 & 18.36 & 11.81 \\
\hline $\mathrm{IOF} \quad \mathrm{A} 1 * \mathrm{~S} 7250$ & 16.14 & 2.48 & 23.43 & 13.60 & 24.40 & 16.05 & 26.99 & 14.29 \\
\hline IOF A $1 * S 7275$ & 17.14 & 2.48 & 26.51 & 14.37 & 26.22 & 16.52 & 30.61 & 15.05 \\
\hline IOF $\mathrm{A} 1 * \mathrm{~S} 72100$ & 18.91 & 2.48 & 29.11 & 14.95 & 28.04 & 16.95 & 33.67 & 15.60 \\
\hline IOF $\quad \mathrm{A} 1 * \mathrm{~S} 82$ & 19.85 & 7.25 & 19.41 & 18.29 & 21.61 & 24.19 & 22.27 & 20.11 \\
\hline IOF A1*S92 & 16.51 & 3.96 & 19.41 & 15.18 & 22.26 & 19.62 & 22.27 & 16.35 \\
\hline IOF $\quad$ A1*S924 & 14.59 & 3.93 & 18.99 & 14.93 & 21.57 & 19.22 & 19.90 & 15.23 \\
\hline IOF A1*S925 & 13.45 & 3.89 & 18.62 & 14.70 & 20.88 & 18.80 & 18.36 & 14.44 \\
\hline IOF A1*S9250 & 18.97 & 3.96 & 23.43 & 17.00 & 24.05 & 20.45 & 26.99 & 18.22 \\
\hline IOF A1*S9275 & 20.73 & 3.96 & 26.51 & 18.23 & 25.84 & 21.23 & 30.61 & 19.46 \\
\hline IOF $\mathrm{A} 1 * \mathrm{~S} 92100$ & 24.66 & 3.96 & 29.11 & 19.18 & 27.64 & 21.96 & 33.67 & 20.40 \\
\hline IOF A2S72 & 15.03 & 2.55 & 19.41 & 12.56 & 22.59 & 15.80 & 22.37 & 13.34 \\
\hline IOF A2S82 & 20.70 & 7.44 & 19.41 & 18.39 & 21.61 & 24.37 & 22.37 & 20.32 \\
\hline IOF A2S92 & 17.08 & 4.06 & 19.41 & 15.30 & 22.26 & 19.83 & 22.37 & 16.55 \\
\hline IOF $\quad$ A2*S72 & 15.87 & 2.68 & 19.41 & 12.77 & 22.59 & 16.24 & 22.56 & 13.74 \\
\hline IOF $\quad$ A $2 * S 724$ & 14.37 & 2.65 & 18.99 & 12.56 & 21.89 & 15.92 & 20.25 & 12.95 \\
\hline $\mathrm{IOF} \quad \mathrm{A} 2 * \mathrm{~S} 725$ & 13.33 & 2.66 & 18.62 & 12.46 & 21.19 & 15.72 & 18.77 & 12.48 \\
\hline $\mathrm{IOF} \quad \mathrm{A} 2 * \mathrm{~S} 7250$ & 17.15 & 2.68 & 23.43 & 14.04 & 24.40 & 16.80 & 27.35 & 15.02 \\
\hline IOF $\quad$ A $2 * S 7275$ & 18.17 & 2.68 & 26.51 & 14.87 & 26.22 & 17.31 & 31.02 & 15.85 \\
\hline
\end{tabular}




\begin{tabular}{lcccccccc}
\hline \multirow{2}{*}{ Specimen } & \multicolumn{2}{c}{ Numerical result } & \multicolumn{2}{c}{ EN1993-1-3 } & \multicolumn{2}{c}{ SEI/ASCE 8-02 } & \multicolumn{2}{c}{ Proposal } \\
\cline { 3 - 9 } & $\begin{array}{c}\mathrm{R}_{\mathrm{u}, \text { num }} \\
(\mathrm{kN})\end{array}$ & $\begin{array}{c}\mathrm{M}_{\mathrm{c}, \text { num }} \\
(\mathrm{kNm})\end{array}$ & $\begin{array}{c}\mathrm{R}_{\mathrm{w}, \mathrm{Rd}} \\
(\mathrm{kN})\end{array}$ & $\begin{array}{c}\mathrm{R}_{\mathrm{WC}-\mathrm{BD}} \\
(\mathrm{kN})\end{array}$ & $\begin{array}{c}\mathrm{R}_{\mathrm{w}, \mathrm{Rd}} \\
(\mathrm{kN})\end{array}$ & $\begin{array}{c}\mathrm{R}_{\mathrm{WC}-\mathrm{BD}} \\
(\mathrm{kN})\end{array}$ & $\begin{array}{c}\mathrm{R}_{\mathrm{w}, \mathrm{Rd}} \\
(\mathrm{kN})\end{array}$ & $\begin{array}{c}\mathrm{R}_{\mathrm{WC}-\mathrm{BD}} \\
(\mathrm{kN})\end{array}$ \\
\hline IOF A2*S72100 & 20.20 & 2.68 & 29.11 & 15.49 & 28.04 & 17.78 & 34.11 & 16.46 \\
IOF A2*S82 & 22.77 & 7.72 & 19.41 & 18.49 & 21.61 & 24.65 & 22.56 & 20.66 \\
IOF A2*S92 & 18.25 & 4.27 & 19.41 & 15.50 & 22.26 & 20.28 & 22.56 & 16.98 \\
IOF A2*S924 & 16.33 & 4.25 & 18.99 & 15.26 & 21.57 & 19.88 & 20.25 & 15.86 \\
IOF A2*S925 & 15.85 & 4.24 & 18.62 & 15.06 & 20.88 & 19.51 & 18.77 & 15.11 \\
IOF A2*S9250 & 20.42 & 4.27 & 23.43 & 17.41 & 24.05 & 21.18 & 27.35 & 18.98 \\
IOF A2*S9275 & 22.01 & 4.27 & 26.51 & 18.71 & 25.84 & 22.01 & 31.02 & 20.32 \\
IOF A2*S92100 & 25.48 & 4.27 & 29.11 & 19.70 & 27.64 & 22.79 & 34.11 & 21.33 \\
\hline
\end{tabular}

Table A3. Numerical and predicted resistances for SHS/RHS under EOF loading

\begin{tabular}{|c|c|c|c|c|}
\hline \multirow{2}{*}{ Specimen } & Numerical result & EN1993-1-3 & SEI/ASCE 8-02 & Proposal $^{*}$ \\
\hline & $\mathrm{R}_{\mathrm{u}, \text { num }}(\mathrm{kN})$ & $\mathrm{R}_{\mathrm{w}, \mathrm{Rd}}(\mathrm{kN})$ & $\mathrm{R}_{\mathrm{w}, \mathrm{Rd}}(\mathrm{kN})$ & $\mathrm{R}_{\mathrm{w}, \mathrm{Rd}}(\mathrm{kN})$ \\
\hline EOF $\quad$ A1*S1250 & 19.86 & 10.33 & 10.63 & 10.21 \\
\hline EOF $A 1 * S 5275$ & 21.78 & 10.33 & 11.70 & 10.42 \\
\hline EOF $\quad A 1 * S 52100$ & 23.22 & 10.33 & 12.76 & 10.60 \\
\hline EOF $\mathrm{A} 1 * \mathrm{~S} 521002$ & 18.52 & 10.33 & 9.57 & 9.94 \\
\hline EOF $\quad A 1 * S 62$ & 17.75 & 10.33 & 8.96 & 9.94 \\
\hline EOF $\quad \mathrm{A} 1 * \mathrm{~S} 624$ & 15.90 & 10.11 & 8.24 & 9.68 \\
\hline EOF $\mathrm{A} 1 * \mathrm{~S} 625$ & 14.31 & 9.91 & 7.51 & 9.72 \\
\hline EOF A2S62 & 18.62 & 10.33 & 8.96 & 10.10 \\
\hline EOF $\mathrm{A} 2 * \mathrm{~S} 5250$ & 22.18 & 10.33 & 10.64 & 10.68 \\
\hline EOF $\quad \mathrm{A} 2 * \mathrm{~S} 5275$ & 24.96 & 10.33 & 11.70 & 10.90 \\
\hline EOF $\quad$ A $2 * S 52100$ & 26.72 & 10.33 & 12.76 & 11.08 \\
\hline EOF $\quad$ A2*S521002 & 21.41 & 10.33 & 9.57 & 10.40 \\
\hline EOF $\quad$ A $2 * S 62$ & 20.16 & 10.33 & 8.96 & 10.40 \\
\hline EOF $\quad$ A $2 * S 624$ & 18.03 & 10.11 & 8.24 & 10.27 \\
\hline EOF $\quad$ A2*S625 & 16.16 & 9.91 & 7.51 & 10.47 \\
\hline EOF A1S64 & 53.58 & 38.14 & 39.59 & 46.13 \\
\hline EOF $\mathrm{A} 1 * \mathrm{~S} 5450$ & 61.18 & 38.14 & 43.23 & 47.23 \\
\hline EOF $\quad$ A $1 * S 5475$ & 69.13 & 38.14 & 45.64 & 47.93 \\
\hline EOF $\quad A 1 * S 54100$ & 75.74 & 38.14 & 48.04 & 48.52 \\
\hline EOF $\quad$ A $1 * S 541002$ & 60.04 & 38.14 & 40.83 & 46.32 \\
\hline EOF $\quad \mathrm{A} 1 * \mathrm{~S} 64$ & 55.36 & 38.14 & 39.59 & 46.32 \\
\hline EOF $A 1 *$ S644 & 52.02 & 37.58 & 39.59 & 42.52 \\
\hline EOF $\mathrm{A} 1 * \mathrm{~S} 645$ & 48.77 & 37.08 & 38.10 & 40.31 \\
\hline EOF A2S64 & 58.64 & 38.14 & 39.59 & 46.68 \\
\hline $\mathrm{EOF} \quad \mathrm{A} 2 * \mathrm{~S} 5450$ & 69.58 & 38.14 & 43.23 & 48.29 \\
\hline $\mathrm{EOF} \quad \mathrm{A} 2 * \mathrm{~S} 5475$ & 80.44 & 38.14 & 45.64 & 49.01 \\
\hline EOF $\quad$ A $2 * S 54100$ & 89.25 & 38.14 & 48.04 & 49.62 \\
\hline EOF $\quad$ A $2 * S 541002$ & 75.02 & 38.14 & 40.83 & 47.36 \\
\hline EOF $\quad$ A $2 * S 64$ & 64.80 & 38.14 & 39.59 & 47.36 \\
\hline EOF $\quad$ A2*S644 & 61.16 & 37.58 & 39.59 & 43.79 \\
\hline EOF $\quad$ A2*S645 & 57.30 & 37.08 & 38.10 & 41.83 \\
\hline
\end{tabular}

${ }^{*}$ After readjustment 
Table A4. Numerical and predicted resistances for hat sections under EOF loading

\begin{tabular}{|c|c|c|c|c|c|}
\hline \multirow{2}{*}{\multicolumn{2}{|c|}{ Specimen }} & \multirow{2}{*}{$\begin{array}{c}\text { Numerical result } \\
\mathrm{R}_{\mathrm{u}, \mathrm{num}}(\mathrm{kN})\end{array}$} & \multirow{2}{*}{$\begin{array}{l}\text { EN1993-1-3 } \\
\mathrm{R}_{\mathrm{w}, \mathrm{Rd}}(\mathrm{kN}) \\
\end{array}$} & \multirow{2}{*}{$\begin{array}{c}\text { SEI/ASCE 8-02 } \\
\mathrm{R}_{\mathrm{w}, \mathrm{Rd}}(\mathrm{kN}) \\
\end{array}$} & \multirow{2}{*}{$\begin{array}{c}\text { Proposal }^{*} \\
\mathrm{R}_{\mathrm{w}, \mathrm{Rd}}(\mathrm{kN}) \\
\end{array}$} \\
\hline & & & & & \\
\hline EOF & A1S81 & 3.13 & 2.15 & 1.58 & 1.99 \\
\hline EOF & $\mathrm{A} 1 * \mathrm{~S} 81$ & 3.17 & 2.15 & 1.58 & 2.01 \\
\hline $\mathrm{EOF}$ & $\mathrm{A} 1 * \mathrm{~S} 814$ & 2.87 & 2.08 & 1.24 & 2.01 \\
\hline $\mathrm{EOF}$ & $\mathrm{A} 1 * \mathrm{~S} 815$ & 2.66 & 2.02 & 1.13 & 2.07 \\
\hline EOF & $\mathrm{A} 1 * \mathrm{~S} 9140$ & 4.16 & 2.15 & 2.00 & 2.06 \\
\hline $\mathrm{EOF}$ & $\mathrm{A} 1 * \mathrm{~S} 9150$ & 4.79 & 2.15 & 2.14 & 2.09 \\
\hline EOF & A2S81 & 3.25 & 2.15 & 1.58 & 2.05 \\
\hline $\mathrm{EOF}$ & $\mathrm{A} 2 * \mathrm{~S} 81$ & 3.40 & 2.15 & 1.58 & 2.12 \\
\hline $\mathrm{EOF}$ & $\mathrm{A} 2 * \mathrm{~S} 814$ & 3.12 & 2.08 & 1.24 & 2.15 \\
\hline EOF & $\mathrm{A} 2 * \mathrm{~S} 815$ & 2.92 & 2.02 & 1.13 & 2.26 \\
\hline EOF & $\mathrm{A} 2 * \mathrm{~S} 9140$ & 4.35 & 2.15 & 2.00 & 2.17 \\
\hline $\mathrm{EOF}$ & $\mathrm{A} 2 * \mathrm{~S} 9150$ & 4.97 & 2.15 & 2.14 & 2.20 \\
\hline $\mathrm{EOF}$ & A1S82 & 11.93 & 7.85 & 8.96 & 8.91 \\
\hline EOF & $\mathrm{A} 1 * \mathrm{~S} 82$ & 12.13 & 7.85 & 8.96 & 8.95 \\
\hline EOF & $\mathrm{A} 1 * \mathrm{~S} 824$ & 10.86 & 7.68 & 8.24 & 8.33 \\
\hline $\mathrm{EOF}$ & $\mathrm{A} 1 * \mathrm{~S} 825$ & 9.83 & 7.53 & 7.51 & 7.99 \\
\hline $\mathrm{EOF}$ & $\mathrm{A} 1 * \mathrm{~S} 9240$ & 16.61 & 7.85 & 10.08 & 9.11 \\
\hline EOF & $\mathrm{A} 1 * \mathrm{~S} 9250$ & 19.45 & 7.85 & 10.50 & 9.20 \\
\hline EOF & $\mathrm{A} 2 \mathrm{~S} 82$ & 12.53 & 7.85 & 8.96 & 9.04 \\
\hline EOF & $\mathrm{A} 2 * \mathrm{~S} 82$ & 13.33 & 7.85 & 8.96 & 9.19 \\
\hline EOF & $\mathrm{A} 2 * \mathrm{~S} 824$ & 12.13 & 7.68 & 8.24 & 8.62 \\
\hline EOF & $\mathrm{A} 2 * \mathrm{~S} 825$ & 10.89 & 7.53 & 7.51 & 8.35 \\
\hline EOF & $\mathrm{A} 2 * \mathrm{~S} 9240$ & 17.91 & 7.85 & 10.08 & 9.35 \\
\hline $\mathrm{EOF}$ & $\mathrm{A} 2 * \mathrm{~S} 9250$ & 20.77 & 7.85 & 10.50 & 9.44 \\
\hline
\end{tabular}

*After readjustment 


\section{References}

ANSI/ASCE 8-90 (1991). Specification for the design of cold-formed stainless steel structural members. Reston, Virginia.

SEI/ASCE 8-02 (2002). Specification for the design of cold-formed stainless steel structural members. Reston, Virginia.

Baddoo, N.R. and Francis, P. (2012). "Development of design rules in the AISC Design Guide for Structural Stainless Steel." $4^{\text {th }}$ International Stainless Steel Experts Seminar, Ascot, UK.

Baddoo, N.R. and Francis, P. (2013). Re-evaluation of EN 1993-1-4 partial resistance factors. SCI report RT1533, The Steel Construction Institut, Ascot, UK.

Baehre, R. (1975). "Sheet metal panels for use in building construction- Recent research projects in Sweden." Proc. of the $3^{\text {rd }}$ International Specialty Conf. On Cold-Cormed Steel Structures, University of Missouri-Rolla, Rolla, Missouri, USA, pp. 383-455.

Bakker, M.C.M. and Stark, J.W.B. (1994). "Theoretical and experimental research on web crippling of cold-formed flexural steel members." Thin-Walled Structures, 18(4), pp. 261-290.

Bhakta, B.H., LaBoube, R.A. and Yu, W.W. (1992). The effect of flange restraint on web crippling strength. Final Report, Civil Engineering Study 92-1, University of Missouri-Rolla, Rolla, Missouri, USA.

Bock, M., Arrayago, I., Real, E. and Mirambell, E (2013). "Study of web crippling in ferritic stainless steel cold-formed sections." Thin-Walled Structures, 69(4), pp. 29-44.

Cain, D. E., LaBoube, R.A. and Yu, W.W. (1995). The effect of flange restraint on web crippling strength of cold formed steel Z-and I-Sections. Final Report, Civil Engineering Study 95-2, University of Missouri-Rolla, Rolla, Missouri, USA.

Chacón, R., Braun, B., Kuhlman, U. and Mirambell, E. (2012). "Statistical evaluation of the new resistance model for steel plate girders subjected to patch loading." Steel Construction, 5(1), pp. 10-15.

Davaine, L. (2005). Formulations de la résistance au lancement d'une âme métallique de pont raidie longitudinalement - Résistance dite de "Patch Loading". Dissertation, L'Institut National des Sciences Appliquées de Rennes, France. 
EN 1990 (2002). Eurocode 0: Basis of structural design. Brussels, Belgium.

EN 1993-1-3 (2006). Eurocode 3: Design of steel structures - Part 1.3: General rules Supplementary rules for cold-formed members and sheeting. Brussels, Belgium.

EN 1993-1-4 (2006). Eurocode 3: Design of steel structures - Part 1.4: General rules Supplementary rules for stainless steel. Brussels, Belgium.

Gabeler, L. (2009). Statistical evaluation of patch loading resistance models for welded steel girders. Diploma Thesis, Institute of Structural Design, University of Stuttgart, Germany.

Gardner, L., Talja, A. and Baddoo, N.R. (2006). "Structural design of high-strength austenitic stainless.” Thin-Walled Structures, 44(5), pp. 517-528.

Gerges, R. R. (1997). Web crippling of single web cold-formed steel members subjected to end one-flange loading. MSc. Dissertation, University of Waterloo, Waterloo, Ontario, Canada.

Hetrakul, N. and Yu, W.W. (1978). Structural behavior of beam webs subjected to web crippling and a combination of web crippling and bending. Final Report, Civil Engineering Study 78-4, University of Missouri-Rolla, Rolla, Missouri, USA.

Hofmeyer, H., Kerstens, J.G.M., Snijder, H.H., Bakker, M.C.M. (2001). “ New prediction model for failure of steel sheeting subject to concentrated load (web crippling) and bending." Thin-Walled Structures, 39(9), pp. 773-796.

Korvink, S.A, van den Berg, G.J. and van der Merwe, P. (1995). "Web crippling of stainless steel cold-formed beams." Journal of Constructional Steel Research, 34(2-3), pp. 225-248.

NASPEC-2001 (2001). North American specification for the design of cold-formed steel structural members. Washington, DC.

Packer, J. A. (1984). "Web crippling of rectangular hollow sections." Journal of Structural Engineering, ASCE, 110(10), pp. 2357-2373.

Prabhakaran, K. (1993). Web crippling of cold-formed steel sections. Project Report, Department of Civil Engineering, University of Waterloo, Waterloo, Ontario, Canada. 
Santaputra, C., Parks, M.B. and Yu, W.W (1989). "Web crippling strength of coldformed steel beams." Journal of Structural Engineering, ASCE, 115(10), pp. 25112527.

Studnicka, J. (1990). "Web crippling of wide deck sections." Proc. of the $10^{\text {th }}$ International Specialty Conf. On Cold-Cormed Steel Structures, University of MissouriRolla, Rolla, Missouri, USA, pp. 317-334.

Talja, A. and Salmi, P. (1995). Design of stainless steel RHS beams, columns and beamcolumns. VTT Research Notes 1619. VTT Technical Research Centre of Finland, Espoo, Finland.

Talja, A. (2004). Work packages 2 and 3: Test results of RHS, top hat and sheeting profiles. Report to the RFCS Project - Structural design of austenitic cold-worked stainless steel, Contract no. 7210 PR/ 318, VTT Technical Research Centre of Finland, Espoo, Finland.

Talja, A. and Hradil, P. (2011). Work package 2: Model calibration tests - Test Report. Report to the RFCS Project - Structural applications of ferritic stainless steel (SAFSS), Contract no. RFSR-CT-2010-00026, VTT Technical Research Centre of Finland, Espoo, Finland.

Tsai, Y.M. (1987). Comportement sur appuis de tôles minces formées à froid. Thèse No. 689. Dissertation, Ecole Polytechnique Fédérale de Lausanne, Lausanne, Switzerland.

Wing, B.A. (1981). Web crippling and the interaction of bending and web crippling of unreinforced multi-web cold formed steel sections. MSc. Dissertation, University of Waterloo, Waterloo, Ontario, Canada.

Winter, G. and Pian, R.H.J. (1946). "Crushing strength of thin steel webs." Engineering Experiment Station, Bulletin No. 35, Part 1. Cornell University, New York, USA.

Young, B. and Hancock, G.J. (2001). "Design of cold-formed channels subjected to web crippling." Journal of Structural Engineering, ASCE, 127(10), pp. 1137-44.

Zilli, G. (2004). Work package 3: Cold formed profiles and sheeting - Test results on unstiffened profiles. Report to the RFCS Project - Structural design of austenitic coldworked stainless steel, Contract no. 7210 PR/ 318, Centro Sviluppo Materiali, Rome, Italy.

Zhao, X. L., and Hancock, G. J. (1992). "Square and rectangular hollow sections subject to combined actions." Journal of Structural Engineering, ASCE, 118(3), pp.648-668. 
Zhao, X. L., and Hancock, G. J. (1995). "Square and rectangular hollow sections under transverse end-bearing force." Journal of Structural Engineering, ASCE, 121(9), pp.1323-1329.

Zhou, F. and Young, B. (2006). "Cold-formed stainless steel sections subjected to web crippling." Journal of Structural Engineering, ASCE, 132(1), pp. 134-144.

Zhou, F. and Young, B. (2007a). "Cold-formed high-strength stainless steel tubular sections subjected to web crippling." Journal of Structural Engineering, ASCE, 133(3), pp. 368-377.

Zhou, F. and Young, B. (2007b). "Experimental and numerical investigations of coldformed stainless steel tubular sections subjected to concentrated bearing load." Journal of Constructional Steel Research, 63(11), pp. 1452-1466.

Zhou, F. and Young, B. (2007c). "Experimental investigation of cold-formed highstrength stainless steel tubular members subjected to combined bending and web crippling." Journal of Structural Engineering, ASCE, 133(7), pp. 1027-1034.

Zhou, F. and Young, B. (2008). "Web crippling of cold-formed stainless steel tubular sections." Advances in Structural Engineering, 11(6), pp. 679-691. 